OPEN ACCESS

Edited by:

Kirsten Harvey,

University College London, UK

Reviewed by:

Kurt De Vos,

The University of Sheffield, UK

Austen J. Milnerwood, University of British Columbia,

Canada

${ }^{*}$ Correspondence:

Steven B. Condliffe steven.condliffe@otago.ac.nz

Received: 25 January 2016 Accepted: 06 May 2016

Published: 23 May 2016

Citation:

Bedford C, Sears C, Perez-Carrion M, Piccoli $G$ and Condliffe SB (2016) LRRK2 Regulates Voltage-Gated Calcium Channel Function.

Front. Mol. Neurosci. 9:35. doi: 10.3389/fnmol.2016.00035

\section{LRRK2 Regulates Voltage-Gated Calcium Channel Function}

\author{
Cade Bedford ${ }^{1}$, Catherine Sears ${ }^{1}$, Maria Perez-Carrion ${ }^{2}$, Giovanni Piccoli ${ }^{2,3}$ \\ and Steven B. Condliffe ${ }^{1 *}$
}

${ }^{1}$ Department of Physiology, University of Otago, Dunedin, New Zealand, ${ }^{2}$ Center for Integrative Biology (CIBIO), University of Trento, Trento, Italy, ${ }^{3}$ Dulbecco Telethon Institute, Trento, Italy

Voltage-gated $\mathrm{Ca}^{2+}(\mathrm{Cav})$ channels enable $\mathrm{Ca}^{2+}$ influx in response to membrane depolarization. Cav2.1 channels are localized to the presynaptic membrane of many types of neurons where they are involved in triggering neurotransmitter release. Several signaling proteins have been identified as important Cav2.1 regulators including protein kinases, G-proteins and $\mathrm{Ca}^{2+}$ binding proteins. Recently, we discovered that leucine rich repeat kinase 2 (LRRK2), a protein associated with inherited Parkinson's disease, interacts with specific synaptic proteins and influences synaptic transmission. Since synaptic proteins functionally interact with Cav2.1 channels and synaptic transmission is triggered by $\mathrm{Ca}^{2+}$ entry via Cav2.1, we investigated whether LRRK2 could impact Cav2.1 channel function. Cav2.1 channel properties were measured using whole cell patch clamp electrophysiology in HEK293 cells transfected with Cav2.1 subunits and various LRRK2 constructs. Our results demonstrate that both wild type (wt) LRRK2 and the G2019S LRRK2 mutant caused a significant increase in whole cell $\mathrm{Ca}^{2+}$ current density compared to cells expressing only the Cav2.1 channel complex. In addition, LRRK2 expression caused a significant hyperpolarizing shift in voltagedependent activation while having no significant effect on inactivation properties. These functional changes in Cav2.1 activity are likely due to a direct action of LRRK2 as we detected a physical interaction between LRRK2 and the $\beta 3 \mathrm{Ca}_{\mathrm{v}}$ channel subunit via coimmunoprecipitation. Furthermore, effects on Cav2.1 channel function are dependent on LRRK2 kinase activity as these could be reversed via treatment with a LRRK2 inhibitor. Interestingly, LRRK2 also augmented endogenous voltage-gated $\mathrm{Ca}^{2+}$ channel function in PC12 cells suggesting other Cav channels could also be regulated by LRRK2. Overall, our findings support a novel physiological role for LRRK2 in regulating Cav2.1 function that could have implications for how mutations in LRRK2 contribute to Parkinson's disease pathophysiology.

Keywords: calcium channels, LRRK2, calcium signaling, protein interactions, Parkinson's disease

\section{INTRODUCTION}

Voltage-gated calcium $\left(\mathrm{Ca}_{V}\right)$ channels play critical roles in cell signaling by enabling $\mathrm{Ca}^{2+}$ influx in response to membrane depolarization. $\mathrm{Ca}_{\mathrm{V}} 2.1$ channels, composed of the pore-forming $\alpha 1 \mathrm{~A}$ subunit and accessory $\beta$ and $\alpha 2 \delta$ subunits, are predominantly expressed in neuronal (Westenbroek et al., 1998) and endocrine cells (Mahapatra et al., 2012), clustered in subcellular 
locations specialized for secretion such as the presynaptic membrane of neurons and the secretory pole of endocrine cells. Here, $\mathrm{Ca}_{V} 2.1$ channels provide a rapid, localized increase in intracellular $\mathrm{Ca}^{2+}$ that stimulates vesicle fusion, driving the physiological processes of neurotransmission (Qian and Noebels, 2001) and hormone release (Braun et al., 2008).

To achieve the correct spatial and temporal dynamics required for these processes, $\mathrm{Ca}_{\mathrm{V}} 2.1$ channel activity is stringently controlled by a variety of signaling proteins that interact with intracellular domains of the channel. These include SNARE proteins of the secretion machinery themselves which inhibit $\mathrm{Ca}_{\mathrm{V}} 2.1$ activity to restrict $\mathrm{Ca}^{2+}$ influx to sites of full core-complex assembly (Bezprozvanny et al., 1995; Cohen-Kutner et al., 2010; Condliffe et al., 2010). $\mathrm{Ca}^{2+}$ binding proteins such as calmodulin (DeMaria et al., 2001), parvalbumin and calbindin (Kreiner and Lee, 2006) also participate in the negative feedback function of $\mathrm{Ca}^{2+}$-dependent inactivation, down-regulating $\mathrm{Ca}_{V} 2.1$ activity when intracellular $\mathrm{Ca}^{2+}$ increases. In addition, several protein kinases have been shown to interact with $\mathrm{Ca}_{V} 2.1$ channel subunits to control channel activity. These include protein kinase C (Zamponi et al., 1997), $\mathrm{Ca}^{2+}$ calmodulin-dependent kinase II (Jiang et al., 2008) and glycogen synthase kinase-3 (Zhu et al., 2010). Not surprisingly, genetic defects in $\mathrm{Ca}_{V} 2.1$ channels result in a variety of neurological diseases including migraine, ataxia and epilepsy (Rajakulendran et al., 2012). While many of these disease associated mutations result in a direct lossor gain-of-function of the channel, recent evidence indicates that some mutations also disrupt regulatory interactions with signaling proteins (Serra et al., 2010; Condliffe et al., 2013).

Leucine rich repeat kinase 2 (LRRK2) is a large, multidomain protein belonging to the ROCO family of proteins. Originally identified in screens for genes mutated in familial Parkinson's Disease (Paisán-Ruiz et al., 2004; Zimprich et al., 2004), the pathophysiological effects of mutations in LRRK2 have been the focus of many studies (Li et al., 2009; Dusonchet et al., 2011; Martin et al., 2014). In contrast, less is known regarding the normal physiological role of LRRK2. Potential roles have been described for autophagy (Alegre-Abarrategui et al., 2009; Tong et al., 2010), vesicle trafficking (Piccoli et al., 2011; MacLeod et al., 2013) and cytoskeleton dynamics (Meixner et al., 2011; Law et al., 2014) where LRRK2 has been shown to target important molecular components of these pathways. A growing body of evidence also supports a role for LRRK2 in $\mathrm{Ca}^{2+}$ signaling and homeostasis. LRRK2 was found to activate a $\mathrm{Ca}^{2+} / \mathrm{CaMKK} / \mathrm{AMPK}$ pathway to increase formation of autophagosomes which could be blocked by buffering cytosolic $\mathrm{Ca}^{2+}$ (GómezSuaga et al., 2012). Cherra et al. (2013) demonstrated that neurons expressing mutant LRRK2 had reduced cytosolic $\mathrm{Ca}^{2+}$ buffering capacity and enhanced mitochondrial degradation that could be restored through calcium chelation or inhibition of $\mathrm{Ca}_{V}$ channels. Recently, LRRK2 was found to up-regulate $\mathrm{Na}^{+} / \mathrm{Ca}^{2+}$ exchanger expression and activity to influence $\mathrm{Ca}^{2+}$ dynamics in dendritic cells (Yan et al., 2015).
Based on our previous work showing a presynaptic role for LRRK2 via interactions with SNARE proteins and functional effects on neurotransmission (Piccoli et al., 2011; Cirnaru et al., 2014), we hypothesize that LRRK2 also targets the major presynaptic $\mathrm{Ca}^{2+}$ influx pathway, the $\mathrm{Ca}_{\mathrm{V}} 2.1$ channel, as a further mechanism to modulate intracellular $\mathrm{Ca}^{2+}$ homeostasis. This was investigated in the present study using patch-clamp electrophysiology to characterize how both heterologous and endogenous $\mathrm{Ca}_{\mathrm{V}}$ channel activity is affected by expression of various LRRK2 constructs. We further analyzed a potential interaction between $\mathrm{Ca}_{V}$ channel subunits and LRRK2 via coimmunoprecipitation.

\section{MATERIALS AND METHODS}

\section{Cell Culture and Transfection}

HEK293 cells were grown in a humidified atmosphere of $5 \% \mathrm{CO}_{2}$ at $37^{\circ} \mathrm{C}$ in $\mathrm{DMEM}$ with $10 \% \mathrm{FBS}, 1 \%$ penicillin/streptomycin and $1 \%$ glutamine. PC12 cells were maintained under the same conditions in RPMI-1640 medium supplemented with $10 \%$ horse serum, 5\% FCS and 1\% penicillin/streptomycin. For electrophysiology experiments, both cell types were plated on glass coverslips pre-treated with poly-L-lysine. cDNA encoding for the human $\mathrm{Ca}_{V} 2.1 \alpha 1 \mathrm{~A}$ subunit (NM_001127222) was cloned in pEGFP-C1 to produce an $\alpha 1 \mathrm{~A}$ subunit with an EGFP tag at the c-terminus as described previously (Condliffe et al., 2013). In this prior study, we characterized the protein expression, trafficking and function of the tagged channel. The rat $\beta 3$ subunit DNA (NM_001127222) was cloned in pCMV6 and rabbit $\alpha 2 \delta 1$ (NM_001082276) was cloned in pcDNA3.1. At $24 \mathrm{~h}$ after plating, HEK293 cells were then transfected with the EGFP-tagged $\alpha-1 \mathrm{~A} \mathrm{Ca} \mathrm{V}_{2} 2.1$ channel subunit together with the accessory $\mathrm{Ca}_{\mathrm{V}}$ subunits $\beta 3$ and $\alpha 2 \delta 1$ in a 1:2:2 molar ratio using Lipofectamine 2000 (Invitrogen). HEK293 cells were co-transfected with wildtype (wt) LRRK2, G2019S LRRK2 or wt LRRK1 (1:2:2:1 molar ratio; Table 1) while PC12 cells were transfected with either EGFP alone or EGFP + wt LRRK2. Human LRRK2 (NM_198578.3) was cloned in pcDNA3.0 backbone as described in Gloeckner et al. (2006) while human LRRK1 (NM_024652.4) was cloned in pCMV $-2 \times$ Myc vector as described in Greggio et al. (2007).

\section{Solutions and Reagents}

To inhibit LRRK2 kinase activity in transfected HEK293 cells, the LRRK2 kinase inhibitor LRRK2-IN-1 (Merck; Deng et al., 2011) was added to the cell culture medium $2 \mathrm{~h}$ before electrophysiological recordings at a final concentration of $1 \mu \mathrm{M}$. LRRK2-IN-1 was also added to the external bath solution at the same concentration for recordings from these pre-treated cells. The internal patch pipette solution for both HEK293 and PC12 electrophysiological recordings contained $120 \mathrm{mM}$ $\mathrm{CsMeSO}_{4}^{-}, 10 \mathrm{mM} \mathrm{CsCl}, 10 \mathrm{mM}$ HEPES, $4 \mathrm{mM} \mathrm{Mg-ATP}$, $3 \mathrm{mM}$ Tris-GTP, $2 \mathrm{mM} \mathrm{MgCl}_{2}$ and $1 \mathrm{mM}$ EGTA (pH adjusted to 7.2 with $\mathrm{CsOH}$ ). HEK293 cells were bathed in an external solution containing $145 \mathrm{mM}$ tetraethylammonium chloride, $10 \mathrm{mM}$ HEPES and $5 \mathrm{mM} \mathrm{CaCl}_{2}$. The external 
TABLE 1 | Biophysical properties of HEK293 cells recorded in different experimental conditions.

\begin{tabular}{lcccc}
\hline $\begin{array}{l}\text { Transfection/ } \\
\text { treatment } \\
\text { conditions }\end{array}$ & $\begin{array}{c}\boldsymbol{I}_{\text {max }}(\mathbf{p A}) \\
\text { (mean } \pm \text { SEM) }\end{array}$ & $\begin{array}{c}\mathbf{C m}(\mathbf{p F}) \\
\text { (mean } \pm \text { SEM) }\end{array}$ & $\begin{array}{c}\text { Number } \\
\text { of cells }\end{array}$ & $\begin{array}{c}\text { Number of } \\
\text { independent } \\
\text { experiments }\end{array}$ \\
\hline Cav2.1 & $-396.5 \pm 90.1$ & $30.9 \pm 7.1$ & 12 & 5 \\
$(\alpha 1 \mathrm{~A}, \beta 3, \alpha 2 \delta 1)$ & & & & \\
+LRRK2 & $-763.6 \pm 97.9$ & $31.9 \pm 3.5$ & 12 & 5 \\
+LRRK1 & $-383.1 \pm 85.7$ & $39.3 \pm 5.7$ & 10 & 4 \\
+G2019S & $-992.0 \pm 222.0$ & $26.6 \pm 3.8$ & 9 & 4 \\
+DMSO & $-343.8 \pm 64.3$ & $38.5 \pm 5.8$ & 10 & 4 \\
+LRRK2-IN-1 & $-401.5 \pm 100.0$ & $33.8 \pm 6.1$ & 10 & 4 \\
\hline
\end{tabular}

solution for PC12 recordings contained $115 \mathrm{mM} \mathrm{NaCl}, 4 \mathrm{mM}$ $\mathrm{KCl}, 1 \mathrm{mM} \mathrm{MgCl} 2,10 \mathrm{BaCl}_{2}, 10 \mathrm{mM}$ tetraethylammonium chloride, $10 \mathrm{mM}$ glucose and $10 \mathrm{mM}$ HEPES. TTX was added to this solution immediately prior to recordings at a final concentration of $1 \mu \mathrm{M}$ to block endogenous voltage-gated $\mathrm{Na}^{+}$ currents.

\section{Whole Cell Patch Clamp Electrophysiology} Coverslips containing transfected HEK293 or PC12 cells were transferred to a perfusion chamber containing the appropriate external bathing solution mounted on an IX71 inverted fluorescence microscope (Olympus). Whole cell $\mathrm{Ca}_{V}$ currents were recorded from EGFP positive cells using patch pipettes prepared with a P-2000 puller (Sutter) to resistances measuring 2-3 megohms when filled with internal solution. Peak whole cell $\mathrm{Ca}^{2+}$ or $\mathrm{Ba}^{2+}$ currents were measured using an Axon Axopatch 200B amplifier (Molecular Devices) interfaced to a PC via a Digidata 1320 (Molecular Devices). Series resistance was routinely compensated at $60-80 \%$ and access resistance continually monitored during experiments where cells with uncompensated voltage errors $>5 \mathrm{mV}$ were excluded from analysis. Data were acquired at $10 \mathrm{kHz}$ with leak and capacitative transients subtracted online with a $\mathrm{P} / 4$ protocol using pClamp 10.0 software. Current-voltage $(I-V)$, activation and inactivation curves were acquired and fit with modified Boltzmann functions as described previously (Condliffe et al., 2013).

\section{Immunoblotting and Co-Immunoprecipitation}

To evaluate exogenous LRRK1, wt LRRK2, G2019S LRRK2 and $\mathrm{Ca}_{V} 2.1$ channel subunit protein expression in HEK293 cells as well as LRRK2 silencing in PC-12 cells, transfected cells were solubilized in lysis buffer $(150 \mathrm{mM} \mathrm{NaCl}, 2 \mathrm{mM}$ EDTA, $50 \mathrm{mM}$ Tris-HCl, $1 \%$ NP-40 and $0.25 \%$ sodium deoxicolate, $\mathrm{pH}$ 7.4) by mechanical disaggregation and protein amount evaluated according to Bradford's protocol. About $40 \mu \mathrm{g}$ of total protein was diluted in $25 \% \mathrm{v} / \mathrm{v}$ Laemmli buffer $5 \times$.

For endogenous LRRK2 immunoprecipitation, littermate wt and heterozygous BAC G2019S (Melrose et al., 2010) adult mouse forebrains were cross-linked by incubation with $0.8 \%$ formaldehyde solution for $2 \mathrm{~h}$ under agitation and then extensively washed with cold glycine $0.1 \mathrm{M}$. Brain tissue were then solubilized in lysis buffer $(150 \mathrm{mM} \mathrm{NaCl}, 2 \mathrm{mM}$ EDTA, $50 \mathrm{mM}$ Tris- $\mathrm{HCl}, 1 \% \mathrm{NP}-40$ and $0.25 \%$ sodium deoxicolate, $\mathrm{pH}$ 7.4) by mechanical disaggregation and protein amount evaluated according to Bradford's protocol. One milligram of total protein was incubated with $3 \mu \mathrm{g}$ of rat anti-LRRK2 (clone 24D8, generous gift from Dr. Johannes Gloeckner) or rat anti-IgG (Abcam). Immunocomplexes were precipitated using protein G-Sepharose beads (GE-Healthcare, Freiburg, Germany) and eluted in Laemmli buffer at $55^{\circ} \mathrm{C}$ for $10 \mathrm{~min}$. All samples were loaded onto a $10 \%$ SDS-PAGE and transferred into nitrocellulose membrane at $82 \mathrm{~V}$ for $2 \mathrm{~h}$ at $4^{\circ} \mathrm{C}$. The primary antibodies used were: rabbit anti-LRRK2 at 1:500 (MJFF2, c41-2 Abcam), rabbit anti-calcium channel $\beta 3$ subunit 1:200 (Sigma), rabbit anti-calcium channel $\alpha 1$ a subunit 1:200 (Sigma), mouse anti-actin 1:2000, mouse anti-myc 1:1000 (Sigma), rabbit anti-S6 ribosomal protein (S6RP) 1:1000 (Cell Signalling) applied in blocking buffer (20 mM Tris, $\mathrm{pH} 7.4$, $150 \mathrm{mM} \mathrm{NaCl}, 0.1 \%$ Tween 20) and 5\% nonfat dry milk, overnight at $4^{\circ} \mathrm{C}$. The secondary antibody HRP-conjugated antirabbit (Jackson Immunoresearch) was used at 1:7000 dilution. Proteins were detected using the ECL detection system (GE Healthcare).

Housing and handling of mice were done in compliance with the guidelines established by the European Community Council (Directive 2010/63/EU of March 4th, 2014) and approved by the Italian Ministry of Health (IACUC 625).

\section{Data Analysis}

All data are expressed as the mean \pm SEM of $n$ experiments. Statistical significance between two groups was determined using an unpaired $t$-test at the $p$ level indicated. ANOVA was used for multiple comparisons with a post hoc Tukey's test to identify significant differences between groups at the $p$ level indicated.

\section{RESULTS}

\section{LRRK2 Specifically Increases $\mathrm{Ca}_{\mathrm{v}} \mathbf{2 . 1}$ Function}

To determine whether LRRK2 was able to modulate Cav2.1 channel function, whole cell $\mathrm{Ca}^{2+}$ currents were recorded from HEK293 cells co-expressing LRRK2 and $\mathrm{Ca}_{V} 2.1$ channel subunits. Representative $I-V$ traces generated using a voltagestep protocol demonstrate that larger inward $\mathrm{Ca}^{2+}$ currents were recorded from LRRK2 expressing cells compared to cells transfected only with all three $\mathrm{Ca}_{\mathrm{V}} 2.1$ channel subunits (Figures 1A,B; Table 1). Comparison of the mean $I-V$ relationships shows an increased $\mathrm{Ca}^{2+}$ current density in LRRK2 cells across a range of depolarized voltages (Figure 1C). While LRRK2 increased peak current density, it did not cause a detectable voltage shift in the $I-V$ relationship. Peak $\mathrm{Ca}^{2+}$ current density in both LRRK2 and control cells was observed at $20 \mathrm{mV}$ (Figure 1D), however transfection of LRRK2 resulted in a significantly increased $\mathrm{Ca}^{2+}$ current density at this voltage of $-24.65 \pm 2.81 \mathrm{pA} / \mathrm{pF}(n=12)$ 
A

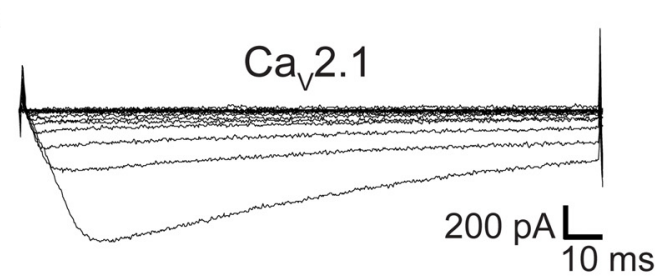

C

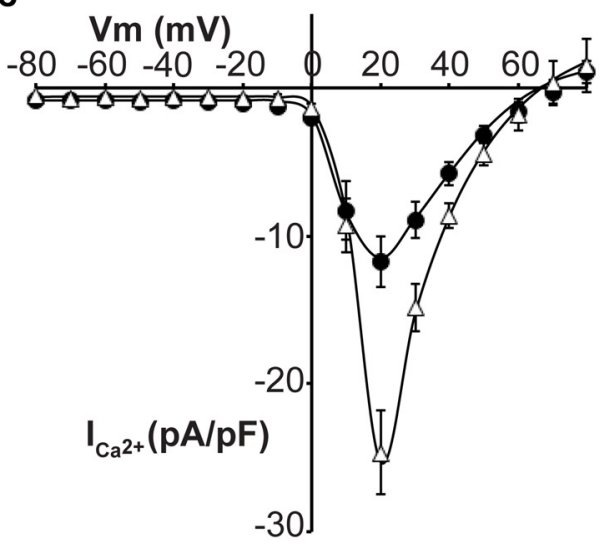

E

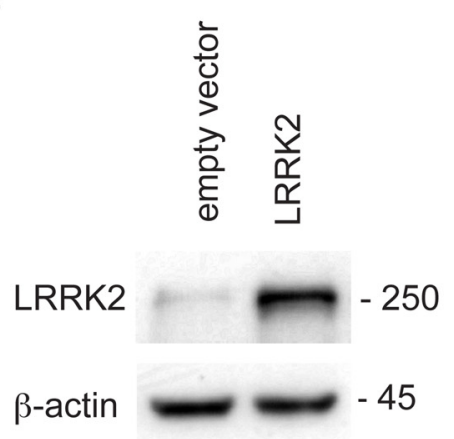

B

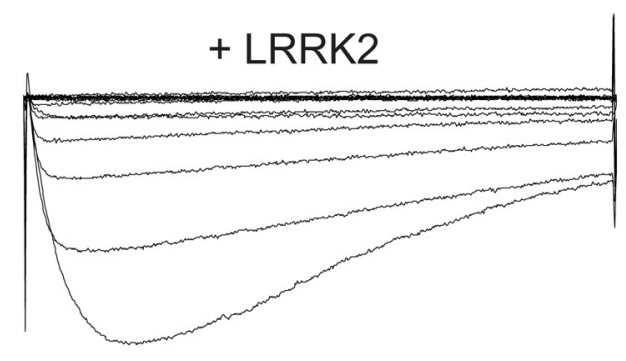

D

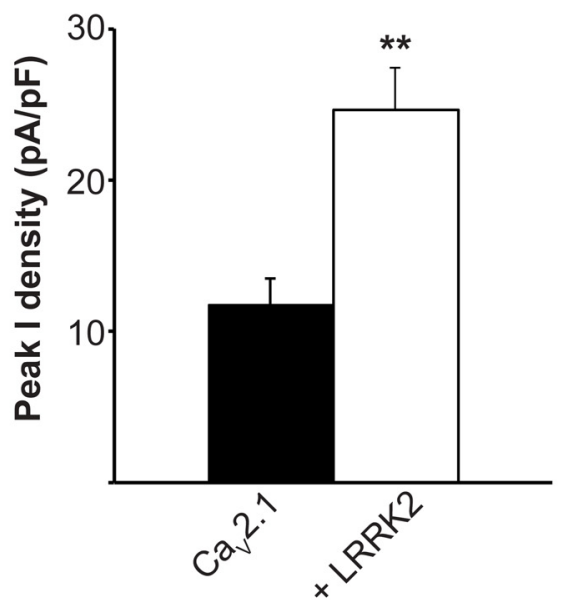

F

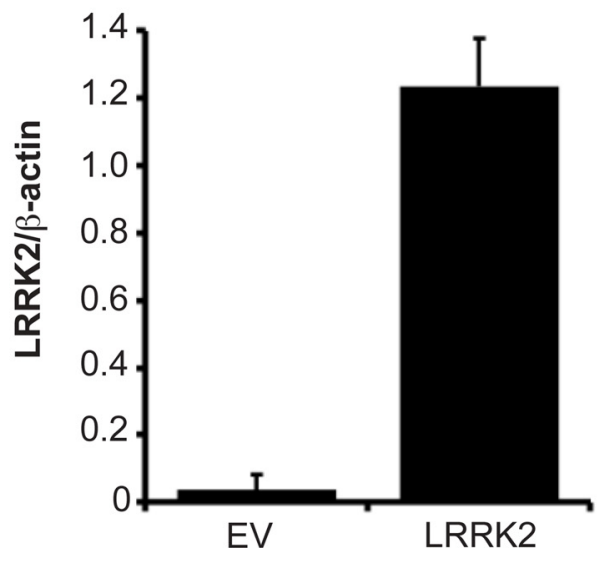

FIGURE 1 | LRRK2 increases Cav2.1 current density. Representative whole cell $\mathrm{Ca}^{2+}$ currents in response to a $10 \mathrm{mV}$ voltage-step protocol recorded from HEK293 cells transfected with Cav2.1 channels alone (A) or together with LRRK2 (B). (C) Mean I-V relationships of peak Ca ${ }^{2+}$ current density from Cav2.1 transfected cells in the absence (black circles) or presence (white triangles) of LRRK2 ( $n=12$ cells from five independent experiments). (D) Mean peak Ca ${ }^{2+}$ current density at a holding potential of $20 \mathrm{mV}$ in cells expressing Cav2.1 alone or co-expressing LRRK2 where ** indicates $p<0.01$; unpaired $t$-test $(n=12$ cells from five independent experiments). (E) HEK293 cells were transfected with empty vector (EV) or wild-type (wt) LRRK2 and expression of LRRK2 was evaluated by western-blotting. (F) The graph reports LRRK2 protein level normalized to the level of endogenous $\beta$-actin. Data are expressed as mean \pm SEM, $(n=8)$.

compared to $-11.76 \pm 1.76 \mathrm{pA} / \mathrm{pF}(n=12)$ in control cells. To confirm LRRK2 overexpression, the amount of LRRK2 protein was measured via western blotting from HEK293 lysates transfected with empty vector (EV) or LRRK2 (Figure 1E). Normalized to endogenous $\beta$-actin expression, results show an elevated level of LRRK2 protein in LRRK2 transfected cells relative to EV controls (Figure 1F). Altogether, these results demonstrate that overexpression of LRRK2 augments Cav2.1 channel function.

In addition to LRRK2, humans and other mammals express a paralog protein, LRRK1, that has the closest sequence homology and shares similar domain structure to 


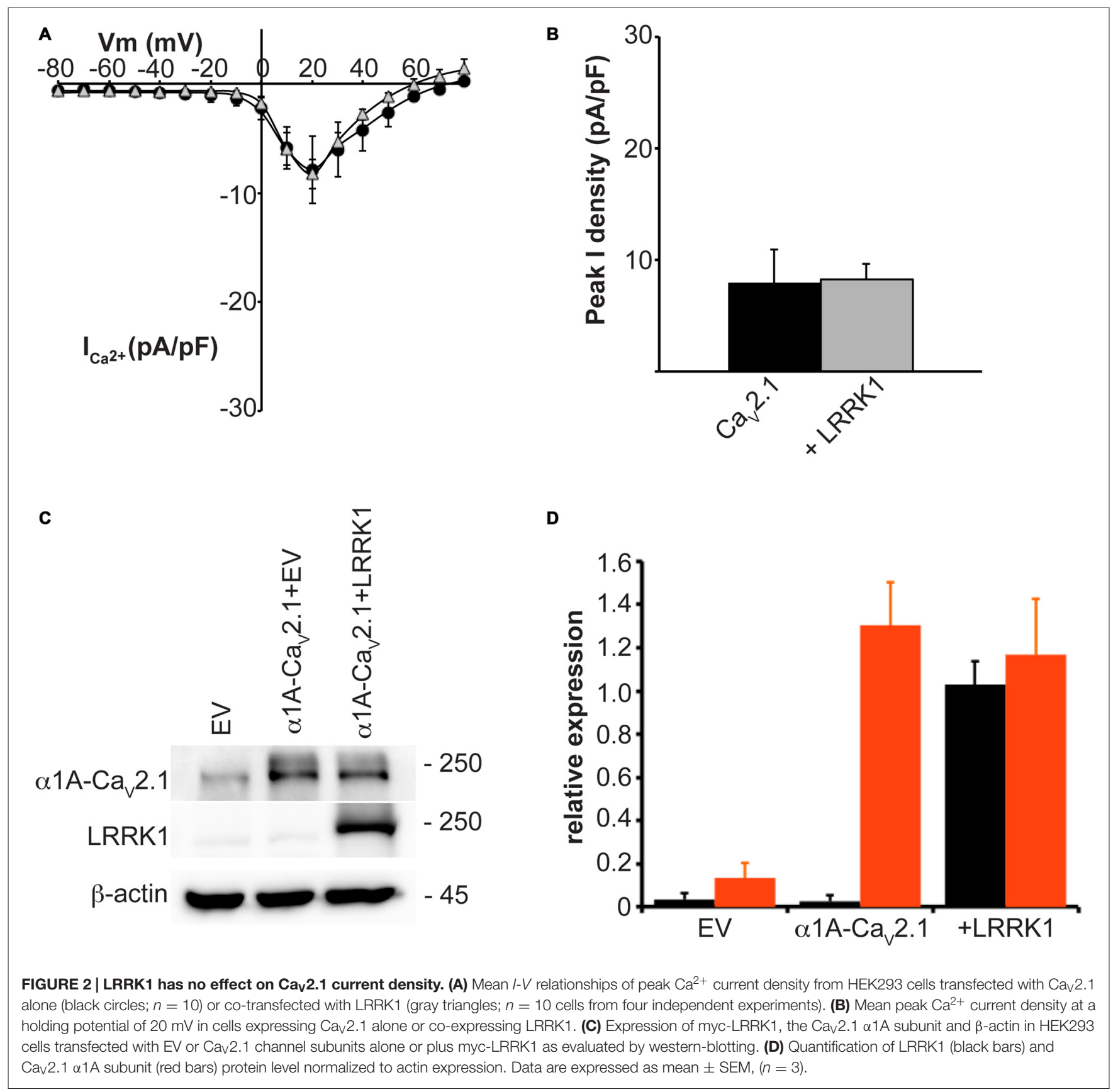

LRRK2. However, LRRK1 is not associated with Parkinson's disease and has differential protein interactions suggesting it performs distinct cellular functions from LRRK2 (Reyniers et al., 2014). To evaluate whether LRRK2 effects on Cav2.1 channel function were specific or could also be replicated by LRRK1, we measured whole cell Cav2.1 properties in HEK293 cells co-transfected with LRRK1. Under these conditions, LRRK1 had no influence on current density across the entire voltage range that was tested (Figure 2A). Peak $\mathrm{Ca}_{\mathrm{V}} 2.1$ current density was not significantly different between cells transfected with all three Cav2.1 channel subunits or co-transfected with LRRK1 (Figure 2B). To confirm exogenous
LRRK1 and $\mathrm{Ca}_{V} 2.1 \alpha 1 \mathrm{~A}$ subunit expression, the amount of LRRK1 and $\alpha 1 \mathrm{~A}$ protein relative to endogenous $\beta$-actin was measured via Western blot (Figure 2C). A robust expression of LRRK1 and $\alpha 1 \mathrm{~A}$ was detected in LRRK1 transfected cells compared to EV controls (Figure 2D). These results confirm that the effect of augmented $\mathrm{Ca}_{V} 2.1$ current is specific to LRRK2. Despite being a homologous protein to LRRK2 in terms of sequence and structure, LRRK1 has no impact on Cav2.1 channel function. It is therefore possible that the effects of LRRK2 on $\mathrm{Ca}_{\mathrm{V}} 2.1$ are mediated by unique LRRK2 domains and/or protein-protein interactions. 
The observed increase in $\mathrm{Ca}_{\mathrm{V}} 2.1$ current density with LRRK2 expression could be caused by LRRK2 increasing $\mathrm{Ca}_{V} 2.1$ channel numbers at the membrane and/or direct effects of the kinase on $\mathrm{Ca}_{\mathrm{V}} 2.1$ channel gating. To provide evidence for the latter, we tested the effects of LRRK2 coexpression on the activation and inactivation gating properties of $\mathrm{Ca}_{V}$ 2.1. Figure 3A shows that LRRK2 caused a hyperpolarizing shift in the voltage-dependence of activation curve. This was associated with a significant hyperpolarization of the halfactivation voltage $\left(\mathrm{V}_{\text {half }}\right)$ from $21.08 \pm 0.69 \mathrm{mV}(n=8)$ in control cells to $16.00 \pm 1.33 \mathrm{mV}(n=9)$ in LRRK2 transfected cells (Figure 3B). This data supports a role for LRRK2 in directly regulating $\mathrm{Ca}_{\mathrm{V}} 2.1$ channel gating by increasing the proportion of activated channels at more hyperpolarized membrane potentials. In contrast, LRRK2 had no effect on inactivation of $\mathrm{Ca}_{v} 2.1$. Voltage-dependent inactivation curves for Cav2.1 were comparable between control and LRRK2 transfected cells (Figure 3C). Also, the halfinactivation voltage in control cells $(-21.33 \pm 1.13 \mathrm{mV}$, $n=6$ ) was not significantly different from that of LRRK2 transfected cells $(-21.54 \pm 2.67 \mathrm{mV}, n=6$; Figure 3D). In addition, we also investigated the effect of LRRK1 on activation properties. As LRRK1 did not significantly alter $\mathrm{Ca}_{V} 2.1$ current density, we hypothesized that LRRK1 would not have any effect on $\mathrm{Ca}_{V} 2.1$ voltage-dependent activation. Our results support this hypothesis showing that voltagedependent activation curves do not differ between control and LRRK1 transfected cells (Figure 3E). Furthermore, no significant difference was detected in the half-activation voltage between control cells $(-19.18 \pm 1.18 \mathrm{mV}, n=8)$ and LRRK1 transfected cells $(-20.36 \pm 1.43 \mathrm{mV}, n=10$; Figure 3F). Overall, these results indicate that LRRK2 regulates $\mathrm{Ca}_{V} 2.1$ channel function via a specific effect on activation gating.

\section{Kinase Activity of LRRK2 is Required to Augment $\mathrm{Ca}_{\mathrm{v}} 2.1$ Function}

Many of the physiological and pathophysiological roles of LRRK2 depend on its kinase activity. To determine whether the effects of LRRK2 on Cav2.1 are linked to its kinase function, we used the LRRK2 kinase mutant G2019S that has increased kinase activity. This mutation enhances the ability of LRRK2 to phosphorylate both itself and other protein substrates (West et al., 2005; Martin et al., 2014). Therefore, if effects of LRRK2 on Cav2.1 function require kinase activity, we hypothesized that the G2019S mutant would have enhanced effects on $\mathrm{Ca}_{V} 2.1$ function. To test this hypothesis, we measured the Cav2.1 current density in HEK293 cells co-transfected with wt or G2019S LRRK2. $I$ - $V$ relationships recorded from cells co-expressing the G2019S LRRK2 mutant exhibited an increase in $\mathrm{Ca}_{V} 2.1$ current density in the voltage ranges of $10-50 \mathrm{mV}$ compared to cells expressing only the three $\mathrm{Ca}_{\mathrm{V}} 2.1$ subunits (Figure 4A). Moreover, G2019S LRRK2 increases current density further than co-expression of wt LRRK2 (Figure 4A). Comparison of the peak $\mathrm{Ca}_{\mathrm{V}} 2.1$ current density in these three conditions confirms that G2019S LRRK2 significantly elevates Cav2.1 current $(-36.50 \pm 4.45 \mathrm{pA} / \mathrm{pF}$; $n=9)$ above both $\mathrm{Ca}_{\mathrm{V}} 2.1(-9.64 \pm 0.90 \mathrm{pA} / \mathrm{pF} ; n=10)$ and wt LRRK2 $(-22.72 \pm 2.78 \mathrm{pA} / \mathrm{pF} ; n=9$; Figure 4B). Since G2019S LRRK2 had a stimulatory effect on Cav2.1 current density, we next examined whether this was also associated with changes to voltage-dependent activation properties. Figure 4C shows that the voltage-dependent activation curve for $\mathrm{Ca}_{V} 2.1$ in the presence of G2019S has shifted to more hyperpolarized potentials compared to controls. G2019S caused a significant decrease in the half-activation voltage from control values of $20.11 \pm 1.0 \mathrm{mV}(n=9)$ to $13.40 \pm 0.61 \mathrm{mV}(n=9$; Figure 4D). To verify that LRRK2 protein expression was similar between G2019S and wt and that it did not affect coexpression levels of $\mathrm{Ca}_{V} 2.1$, we measured the levels of exogenous LRRK2 and $\alpha 1 \mathrm{~A}$ expression in HEK293 cells via Western blot. A representative blot is shown in Figure 4E which reveals that HEK293 cells transfected with EV have minimal LRRK2 protein. However, both wt and G2019S LRRK2 transfected cells have abundant and equivalent LRRK2 and $\alpha 1 \mathrm{~A}$ subunit expression. Normalized to $\beta$-actin levels, wt LRRK2 expression was not significantly different to G2019S expression (Figure 4F). Overall, these results indicate that increased kinase activity of LRRK2 enhances the stimulatory effect on $\mathrm{Ca}_{\mathrm{V}} 2.1$ channels, supporting a role for LRRK2 acting as a kinase to increase Cav2.1 function.

To further demonstrate that LRRK2 kinase activity is required to stimulate Cav2.1, the effect of LRRK2 kinase inhibition was investigated. HEK293 cells co-expressing all three Cav2.1 subunits with either wt or G2019S LRRK2 were pre-treated with LRRK2-IN-1, an inhibitor of both wt and G2019S LRRK2 kinase activity (Deng et al., 2011). Whole cell Cav2.1 current density was then measured and compared to control cells pre-treated with DMSO vehicle. LRRK2 transfected cells pretreated with vehicle had similar increases in $\mathrm{CaV}_{V} 2.1$ current density (Figure 5A) to LRRK2 alone (Figure 1C) demonstrating DMSO did not impact on the stimulatory effect of LRRK2. In contrast, cells that had been pre-treated with LRRK2-IN1 had reduced $\mathrm{Ca}_{V} 2.1$ current densities (Figure 5A) which were comparable to cells expressing $\mathrm{Ca}_{\mathrm{V}} 2.1$ alone (Figure 1C). LRRK2-IN-1 pre-treatment caused a significantly reduced peak $\mathrm{Ca}_{V} 2.1$ current density of $-8.74 \pm 2.71 \mathrm{pA} / \mathrm{pF}(n=10)$ compared to $-24.53 \pm 4.36 \mathrm{pA} / \mathrm{pF}(n=10)$ in vehicle pre-treated controls (Figure 5B).

We also investigated whether LRRK2-IN-1 could reverse the stimulatory effects of the G2019S mutant on $\mathrm{Ca}_{\mathrm{V}} 2.1$ function. Figure 5A demonstrates that whole cell $\mathrm{Ca}_{\mathrm{V}} 2.1$ current density in G2019S LRRK2 transfected cells pre-treated with LRRK2IN-1 was reduced between the voltage range of $10-60 \mathrm{mV}$ compared to vehicle treated cells. A significant difference in peak Cav2.1 current density was observed between LRRK2-IN-1 $(-8.29 \pm 1.86 \mathrm{pA} / \mathrm{pF}, n=10)$ and vehicle $(-35.51 \pm 2.25 \mathrm{pA} / \mathrm{pF}$, $n=10)$ pre-treated cells (Figure $5 \mathbf{B}$ ). Taken together, these results indicate that the stimulatory effects of LRRK2 on Cav2.1 channels are dependent on the ability of LRRK2 to act as a kinase.

Importantly, LRRK2-IN-1 had no effect on CaV2.1 current density in the absence of LRRK2 co-transfection as mean $\mathrm{Ca}_{V} 2.1$ current density was similar between cells tranfected with $\mathrm{Ca}_{V} 2.1$ channels and pre-treated with LRRK2-IN-1 or DMSO 


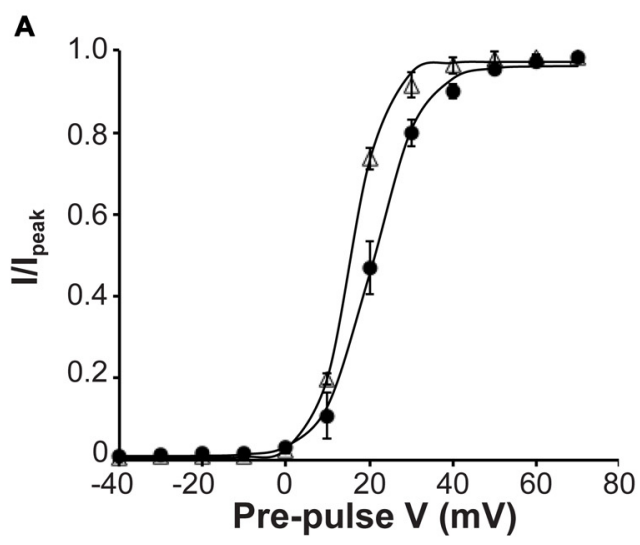

C

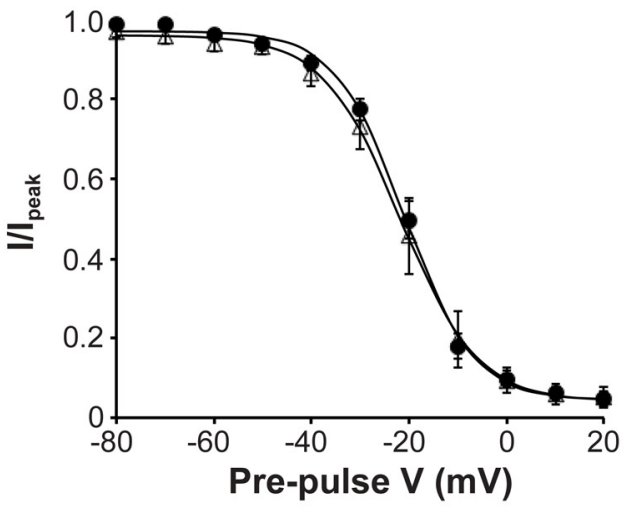

E

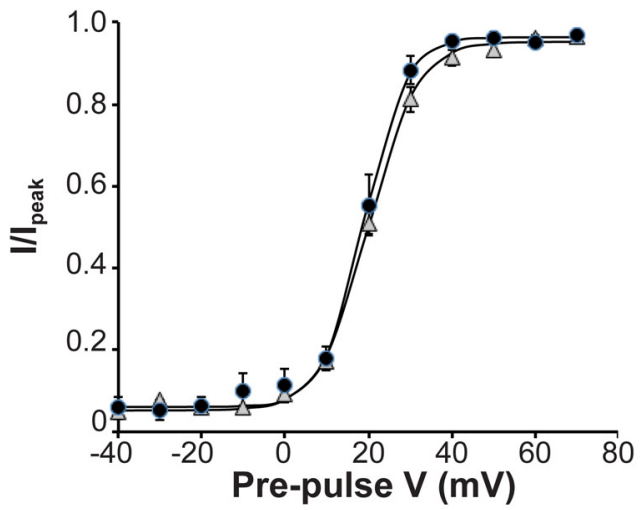

B

$\mathrm{Ca}_{\mathrm{v}} 2.1$

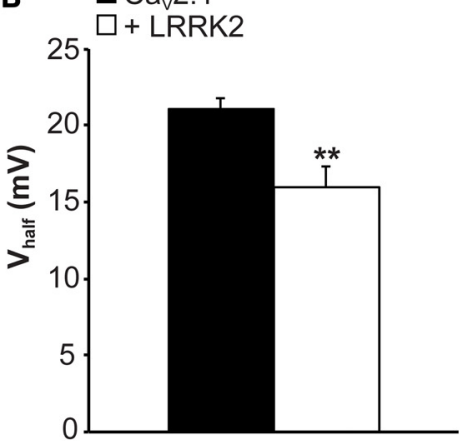

D

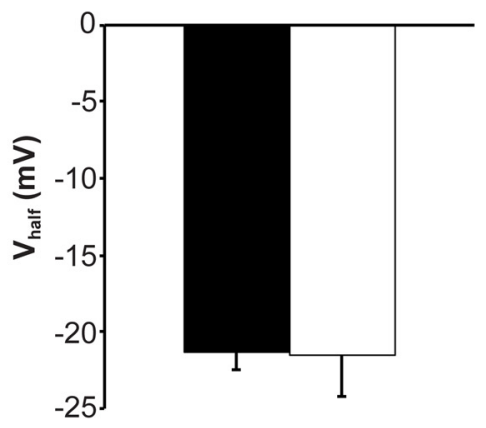

$\mathbf{F}$

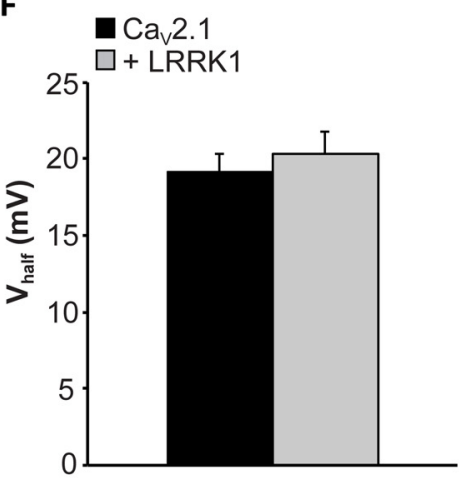

FIGURE 3 | Effect of LRRK2 on Cav2.1 activation and inactivation properties. (A) Voltage dependence of activation curves were recorded from HEK293 cells transfected with Cav2.1 channels alone (black circles; $n=8$ cells from four independent experiments) or co-transfected with LRRK2 (white triangles; $n=9$ cells from four independent experiments). (B) LRRK2 significantly decreased the $V_{\text {half }}$ of Cav2.1 activation compared to control cells (where $* *$ indicates $p<0.01$; unpaired t-test). (C) Voltage dependence of steady-state inactivation curves from HEK293 cells transfected with Cav2.1 channels alone (solid circles) or co-transfected with LRRK2 (open triangles; $n=6$ cells from three independent experiments). (D) LRRK2 had no significant effect on the $V_{\text {half }}$ of Cav2.1 steady-state inactivation compared to control cells. (E) Voltage dependence of activation curves were recorded from HEK293 cells transfected with Cav2.1 channels alone (black circles) or co-transfected with LRRK1 (gray triangles; $n=10$ cells from four independent experiments). (F) LRRK1 had no significant effect on the $V_{\text {half }}$ of Cav2.1 activation compared to control cells.

(Figures 5C,D). This confirms that the effects of the inhibitor are specific to LRRK2 and are not caused by non-specific effects on the channel directly or other channel regulatory proteins.
Next, we investigated the effect that LRRK2-IN-1 had on activation kinetics of $\mathrm{Ca}_{V} 2.1$ channels in cells transfected with LRRK2 and G2019S. Figure 6A illustrates that LRRK2-IN-1 

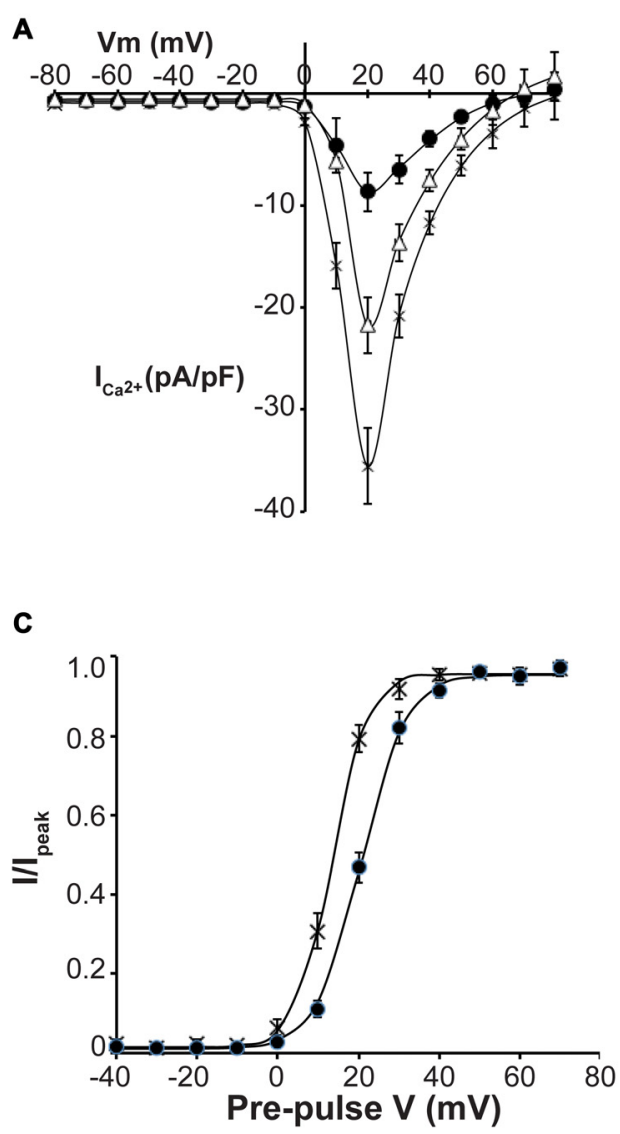

$\mathbf{E}$

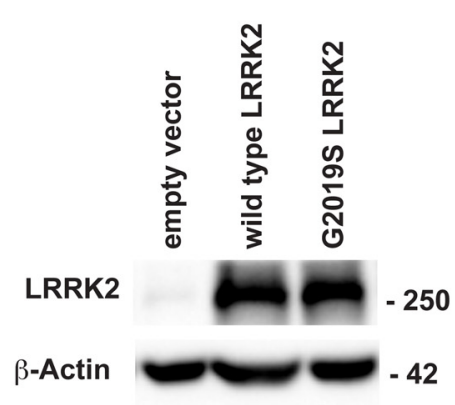

B

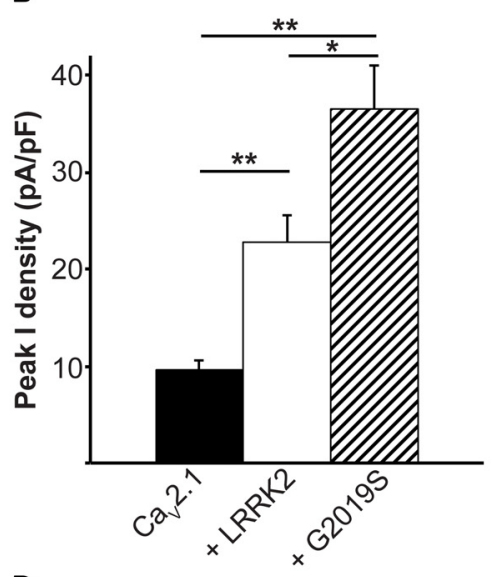

D

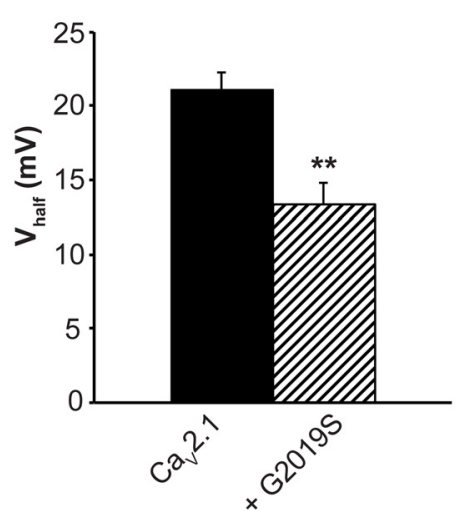

$\mathbf{F}$

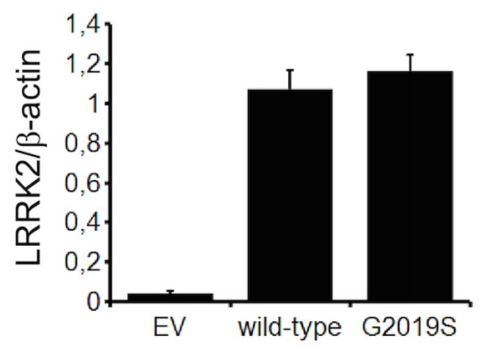

FIGURE 4 | The G2019S LRRK2 mutant causes an additional increase in Cav2.1 current density. (A) Mean I- $V$ relationships of peak Ca ${ }^{2+}$ current density from HEK293 cells transfected with Cav2.1 channels alone (solid circles; $n=10$ cells from four independent experiments) or co-transfected with wt LRRK2 (white triangles; $n=9$ cells from four independent experiments) or G2019S LRRK2 (crosses; $n=9$ cells from four independent experiments). (B) Mean peak Ca ${ }^{2+}$ current density at a holding potential of $20 \mathrm{mV}$ in cells expressing Cav2.1 alone, co-expressing wt LRRK2 or co-expressing G2019S LRRK2. (C) Voltage dependence of activation curves were recorded from HEK293 cells transfected with Cav2.1 channels alone (black circles) or co-transfected with G2019S LRRK2 (crosses; $n=9$ cells from four independent experiments). (D) G2019S LRRK2 significantly decreased the $V_{\text {half }}$ of Cav2.1 activation compared to control cells (where ** indicates $p<0.01$; unpaired $t$-test). (E) HEK293 were transfected with EV, Cav2.1 channel subunits alone or plus wt LRRK2 or G2019S LRRK2. The expression of $\alpha 1 \mathrm{~A}$, wt LRRK2 or G2019S LRRK2 was evaluated by western-blotting. (F) The graph reports LRRK2 (black bars) and Cav2.1 a1A subunit (red bars) protein level normalized vs. actin level. Data are expressed as mean \pm SEM, $(n=8)$.

shifts the voltage-dependent activation curves of both LRRK2 and G2019S cells to more depolarized potentials compared to DMSO treated controls. In cells transfected with LRRK2 and pre-treated with DMSO, the mean half-activation voltage was
$14.08 \pm 1.2 \mathrm{mV}(n=9)$, significantly more hyperpolarized than the value of $20.98 \pm 1.7 \mathrm{mV}(n=9)$ obtained from LRRK2-IN-1 pre-treated cells (Figure 6B). In addition, LRRK2IN-1 pre-treatment significantly depolarized the half-activation 

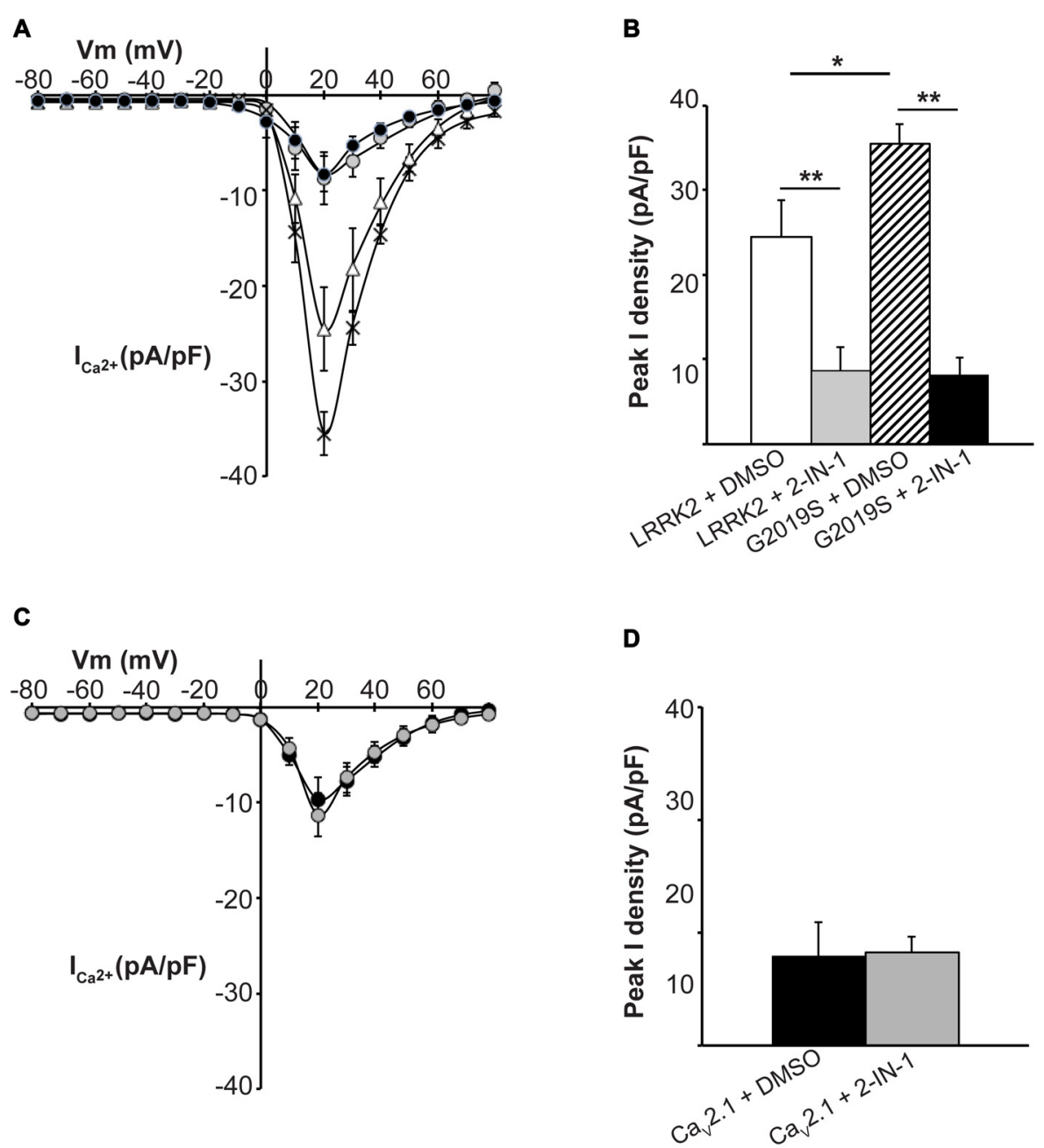

FIGURE 5 | Inhibition of LRRK2 prevents effect on Cav2.1 current density. (A) Mean I-V relationships of peak Ca ${ }^{2+}$ current density from HEK293 cells co-transfected with Cav2.1 and LRRK2 pre-treated with vehicle (white triangles) or the LRRK2 inhibitor LRRK2-IN-1 (gray circles; $n=10$ cells from four independent experiments). Also shown are mean I-V relationships of cells co-transfected with Cav2.1 channels and G2019S pre-treated with vehicle (crosses) or LRRK2-IN-1 (black circles; $n=10$ cells from four independent experiments). (B) LRRK2-IN-1 treated cells had a significantly reduced peak Ca ${ }^{2+}$ current density compared to vehicle (where ${ }^{* *}$ indicates $p<0.01$ ) while peak $\mathrm{Ca}^{2+}$ current density in G2019S cells was still significantly elevated over LRRK2 cells pre-treated with vehicle (where $*$ indicates $p<0.05$ ) and significantly reduced by LRRK2-IN-1 pre-treatment (where ** indicates $p<0.01$; one-way ANOVA). (C) LRRK2-IN-1 pre-treatment (gray circles) had no effect on Cav2.1 current density in the absence of exogenous LRRK2 expression compared to vehicle treated controls (black circles; $n=10$ cells from four independent experiments). (D) Peak $\mathrm{Ca}^{2+}$ current density was comparable between LRRK2-IN-1 pre-treated cells compared to vehicle controls.

voltage of G2019S transfected cells to $22.24 \pm 3.3 \mathrm{mV}(n=8)$ from a mean value of $11.60 \pm 2.7 \mathrm{mV}(n=9$; Figure $6 \mathrm{~B})$. This data indicates that phosphorylation activity of LRRK2 is required to affect changes in activation gating of the Cav2.1 channel. To rule out the possibility that LRRK2-IN-1 acts directly on the $\mathrm{Ca}_{V} 2.1$ channel to alter gating, we examined the effect of LRRK2-IN-1 on voltage-dependent activation of $\mathrm{Ca}_{\mathrm{V}} 2.1$ channels in the absence of exogenous LRRK2 expression. Results from these experiments show that LRRK2-IN-1 has no effect on either the voltage-dependent activation curve (Figure 6C) or the half-inactivation voltage (Figure 6D). Overall, these results indicate that the kinase activity of LRRK2 is required to mediate changes in the activation gating of $\mathrm{Ca}_{V} 2.1$ channels.

\section{LRRK2 Interacts with $\mathrm{Ca}_{\mathrm{v}} 2.1$ Channels}

The function of $\mathrm{Cav}_{v}$ channels can be modulated by regulatory proteins directly interacting with channel subunits (Kiyonaka et al., 2007; Jiang et al., 2008). Since LRRK2 has been shown to interact with a number of presynaptic proteins (Piccoli et al., 2011, 2014), we investigated whether LRRK2 interacts with $\mathrm{Ca}_{V} 2.1$ channel subunits as a mechanism to control channel function. To this aim, we immunoprecipitated endogenous LRRK2 from protein extracted from wt mouse forebrain specimen previously exposed to a cross-linking protocol. Interestingly, we noticed that rat anti LRRK2 but not generic rat IgG precipitates endogenous LRRK2 and the $\mathrm{Ca}_{V}$ channel $\beta 3$ subunit but not the $\mathrm{Ca}_{V}$ channel $\alpha 1$ subunit or SP6 ribosomal protein (Figure 7A). We obtained a similar 

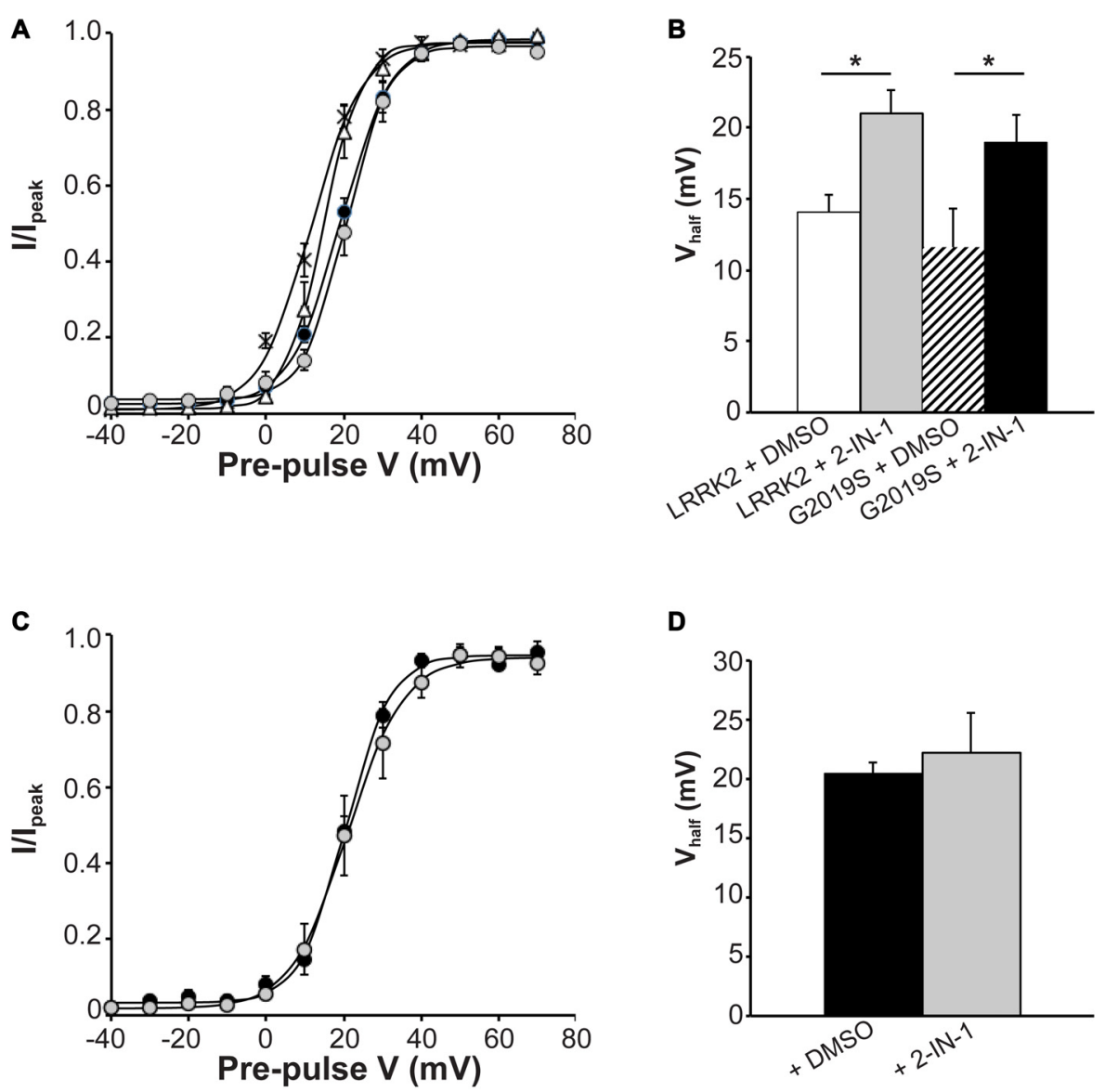

FIGURE 6 | Effect of LRRK2-IN-1 on Cav2.1 activation properties. (A) Voltage dependence of activation curves were recorded from HEK293 cells transfected with Cav2.1 channels plus LRRK2 and pre-treated with LRRK2-IN-1 (gray circles) or DMSO vehicle (white triangles; $n=9$ cells from four independent experiments). A separate group was co-transfected with G2019S and pre-treated with LRRK2-IN-1 (black circles) or DMSO (crosses; $n=9$ cells from four independent experiments). (B) LRRK2-IN-1 significantly increased the $V_{\text {half }}$ of Cav2.1 activation in both LRRK2 and G2019S cells compared to control cells (where * indicates $p<0.05$; one-way ANOVA). (C) Voltage dependence of activation curves from HEK293 cells transfected with Cav2.1 channels alone and pre-treated with DMSO (solid circles) LRRK2-IN-1 (gray circles; $n=10$ cells from four independent experiments). (D) LRRK2-IN-1 had no significant effect on the $V_{\text {half }}$ of Cav2.1 activation compared to control cells.

outcome by immunoprecipitating LRRK2 protein from mouse forebrain specimen obtained from BAC hG2019S LRRK2 mice indicating that $\beta 3$ interacts also with G2019S LRRK2, even though to a significantly reduced extent compared to wt LRRK2 (Figures 7B,C). All together, these data suggest that LRRK2 specifically interacts with the $\mathrm{Ca}_{V} 2.1$ channel $\beta 3$ subunit.

\section{Endogenous $\mathrm{Ca}_{\mathrm{v}}$ Channel Function is Also Increased by LRRK2}

Having established that LRRK2 regulates the function of recombinant $\mathrm{Ca}_{\mathrm{V}} 2.1$ channels, we next investigated whether native $\mathrm{Ca}_{V}$ channels were also subjected to regulation by LRRK2 using the neuroendocrine rat pheochromocytoma PC12 cell line. PC12 cells endogenously express a diversity of $\mathrm{Ca}_{V}$ channels including $\mathrm{Ca}_{V} 1.2, \mathrm{Ca}_{V} 1.3, \mathrm{Ca}_{V} 2.1$ and $\mathrm{Ca}_{V} 2.2$ (Plummer et al., 1989; Liu et al., 1996). To determine whether these native $\mathrm{Ca}_{\mathrm{V}}$ channels were modulated by LRRK2, we transfected PC12 cells with wt LRRK2 plus GFP or GFP alone. $\mathrm{Ba}^{2+}$ was used as the charge carrier to measure $\mathrm{Ca}_{\mathrm{V}}$ currents in $\mathrm{PC} 12$ cells given its higher permeability since endogenous levels of $\mathrm{Ca}_{\mathrm{V}}$ channels were expected to be much smaller than in our heterologous expression system. Indeed, representative $\mathrm{Ba}^{2+}$ current traces recorded from PC12 cells show that GFP-transfected cells have small inward $\mathrm{Ba}^{2+}$ currents (Figure 8A). However, these currents still exhibit the characteristic steep increase between the voltages of -10 to $40 \mathrm{mV}$ typical of high voltage activated $\mathrm{Ca}^{2+}$ channels (Figure 8B). LRRK2 transfection increased the relative amount of current (Figures $\mathbf{8 B}-\mathbf{D}$ ) in this voltage range while GFP transfection had no effect compared to non-transfected controls (Figure 8D). Interestingly, LRRK2 transfection also caused a hyperpolarizing shift in the voltage at which the peak inward $\mathrm{Ba}^{2+}$ current was recorded, from -20 to $-10 \mathrm{mV}$ (Figure 8B). On average, LRRK2 transfection caused a significant increase in peak current density at $20 \mathrm{mV}$ from $-1.86 \pm 0.26 \mathrm{pA} / \mathrm{pF}$ 

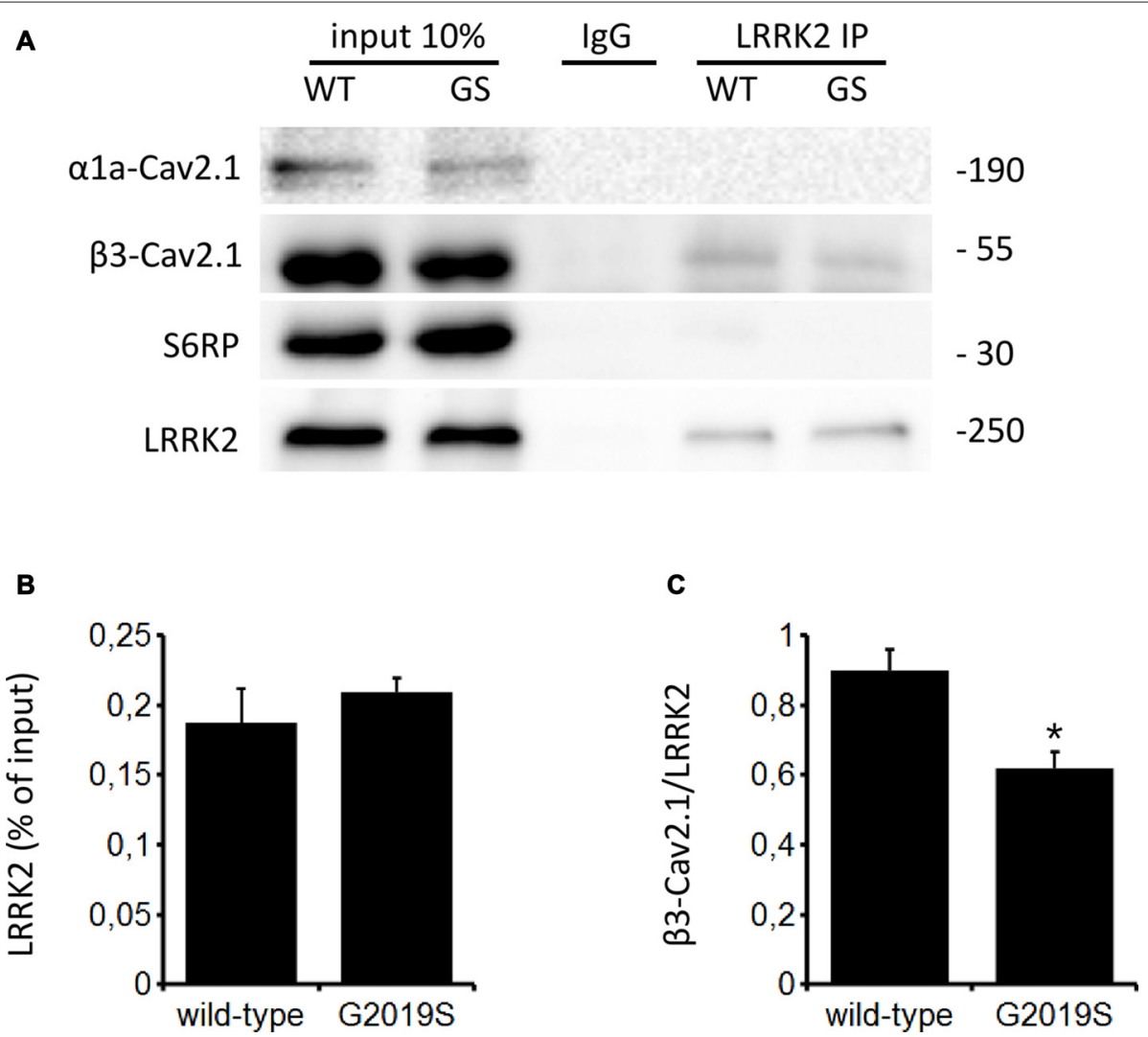

FIGURE 7 | LRRK2 interacts with the Cav2.1 channel. (A) Mouse forebrain specimens obtained from littermate wt and heterozygous BAC hG2019S (GS) mice were cross-linked and then processed for immunoprecipitation with rat anti LRRK2 antibodies. Eluted proteins were resolved by SDS-PAGE and detected with anti LRRK2, anti Cav2.1 33 subunit antibodies, anti Cav2.1 $\alpha$ 1a and anti S6 ribosomal protein (S6RP). (B,C) The graphs report the yield of protein recovered upon LRRK2 immunoprecipitation expressed as a percentage of relative input (B) and as amount of pulled Cav2.1 $\beta 3$ subunit relative to the amount of pulled LRRK2 (C). Bars represent mean $\pm \operatorname{SEM}(n=4)$ where * indicates $p<0.05$; unpaired $t$-test.

$(n=9)$ in GFP transfected cells to $-2.90 \pm 0.24 \mathrm{pA} / \mathrm{pF}(n=7)$ in LRRK2 cells (Figure 8C). No significant difference in peak $\mathrm{Ba}^{2+}$ current density was detected between non-transfected and GFP transfected cells (Figure 8C). To determine whether G2019S LRRK2 also stimulates endogenous Cav channels, whole cell $\mathrm{Ba}^{2+}$ currents were measured in PC12 cells transfected with GFP or G2019S plus GFP. Similar to the effect of wt LRRK2, G2019S caused a large increase in current compared to controls (Figure 8E). In contrast however, there was no apparent shift in the voltage at which peak $\mathrm{Ba}^{2+}$ current was recorded (Figure 8E). This peak current density was at $20 \mathrm{mV}$ where G2019S transfection caused an increase in current from $-1.81 \pm 0.33 \mathrm{pA} / \mathrm{pF}(n=10)$ in GFP transfected cells to $-3.98 \pm 0.73 \mathrm{pA} / \mathrm{pF}(n=10$; Figure $8 \mathrm{~F})$. Finally, to investigate a role for endogenous LRRK2 in regulating native $\mathrm{Ca}_{V}$ channels in PC12 cells, we transfected cells with a LRRK2 silencing construct we had previously used to knockdown LRRK2 in cortical neurons (Piccoli et al., 2011). Figure 9A demonstrates that siLRRK2 cells had reduced $\mathrm{Ba}^{2+}$ currents across several voltages compared to control cells transfected with the EV as performed previously. Peak $\mathrm{Ba}^{2+}$ currents at $20 \mathrm{mV}$ were significantly reduced in siLRRK2 cells (Figure 9B) indicating that endogenous LRRK2 has a physiological role in controlling activity of native $\mathrm{Ca}_{\mathrm{V}}$ channels in PC12 cells. Endogenous LRRK2 protein expression was confirmed in control PC12 cells (Figure 9C) which was significantly reduced in siRNA treated cells (Figure 9D). Taken together, these results suggest that, in addition to stimulating recombinant $\mathrm{Ca}_{\mathrm{V}} 2.1$ channels, LRRK2 is able to up-regulate activity of native $\mathrm{Ca}_{V}$ channels. The fact that PC12 cells express a variety of different $\mathrm{Ca}_{\mathrm{V}}$ channel classes suggests that the effect of LRRK2 is not limited to $\mathrm{Ca}_{V} 2.1$ alone but may also stimulate other $\mathrm{Ca}_{V}$ channel types.

\section{DISCUSSION}

$\mathrm{Ca}_{V} 2.1$ channel activity is regulated by a diversity of kinases and other signaling proteins to control $\mathrm{Ca}^{2+}$ influx and subsequent $\mathrm{Ca}^{2+}$-dependent cellular functions. Here, we demonstrate for the first time that LRRK2 can modulate $\mathrm{Ca}_{V} 2.1$ channel function by causing a large increase in $\mathrm{Ca}^{2+}$ current. This effect was associated with altered $\mathrm{Ca}_{\mathrm{V}} 2.1$ activation properties and was dependent on the kinase activity of LRRK2. These functional effects may be a consequence of a physical interaction between LRRK2 and the $\beta 3$ subunit. Furthermore, LRRK2 also upregulated endogenous $\mathrm{Ca}_{\mathrm{V}}$ channel activity suggesting that 


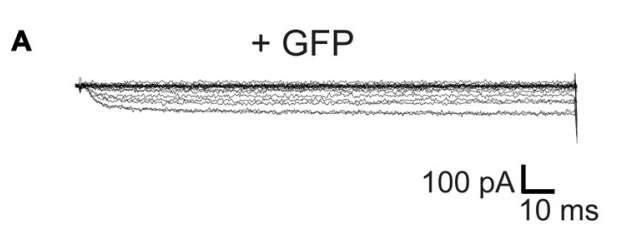

C
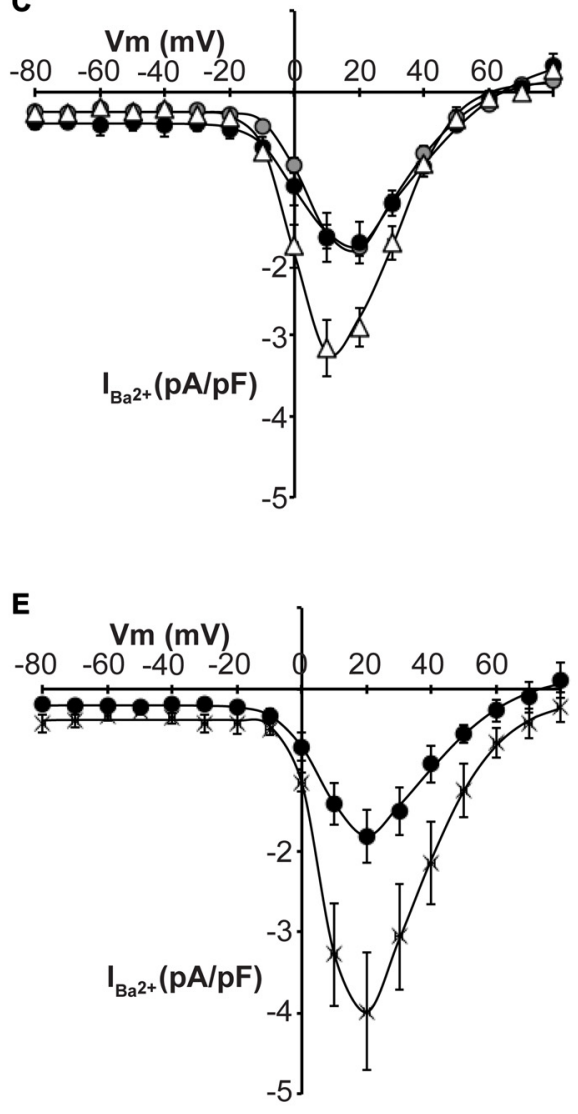

B

+ LRRK2

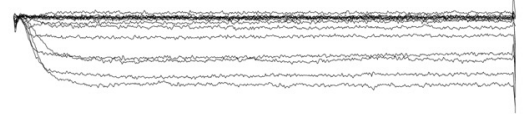

D
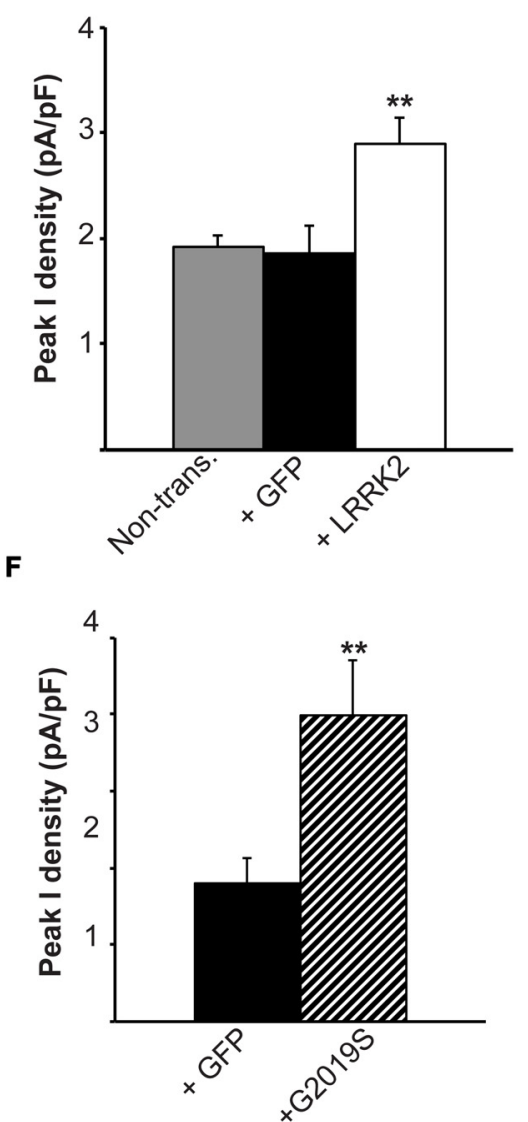

FIGURE 8 | Endogenous Cav channels are stimulated by LRRK2 in PC12 cells. Representative whole cell Ba ${ }^{2+}$ currents recorded from PC12 cells transfected with GFP alone (A) or together with LRRK2 (B). (C) Mean /-V relationships of peak $\mathrm{Ba}^{2+}$ current density from non-transfected (gray circles), GFP transfected (black circles) or LRRK2 transfected PC12 cells (white triangles; $n=7-9$ from four independent experiments). (D) Mean peak Ba ${ }^{2+}$ current density at a holding potential of $20 \mathrm{mV}$ in PC12 cells transfected as described in (C) where ** indicates $p<0.01$, one-way ANOVA. (E) The effect of G2019S LRRK2 (crosses) on Cav current density compared to GFP controls (circles; $n=10$ cells from four independent experiments). (F) Peak Ba ${ }^{2+}$ current density was significantly elevated in G2019S LRRK2 cells compared to vehicle controls (where ** indicates $p<0.01$; unpaired $t$-test).

LRRK2 may have broad effects on a variety of different $\mathrm{Ca}_{\mathrm{V}}$ channels. Altogether, these results describe a novel regulatory mechanism of $\mathrm{Ca}_{\mathrm{V}} 2.1$ channels that is likely to play important roles in both the physiology and pathophysiology of cellular $\mathrm{Ca}^{2+}$ signaling.

Several protein kinases have been shown to target $\mathrm{Ca}_{\mathrm{V}} 2.1$ channels to modulate $\mathrm{Ca}^{2+}$ entry. PKC phosphorylates the I-II linker region of the $\mathrm{Ca}_{V} 2.1 \propto 1 \mathrm{~A}$ subunit to increase $\mathrm{Ca}_{V} 2.1$ current by antagonizing G-protein inhibition of the channel (Zamponi et al., 1997). CaMKII also enhances $\mathrm{Ca}^{2+}$ entry but does so by directly binding to the C-terminus of Cav2.1 to slow inactivation kinetics and cause a depolarizing shift in the voltage-dependence of inactivation (Jiang et al., 2008). In contrast, both Cdk-5 (Tomizawa et al., 2002) and GSK-3 (Zhu et al., 2010) have a negative effect on Cav2.1 function by phosphorylating the II-III loop of $\mathrm{Ca}_{\mathrm{V}} 2.1 \alpha 1 \mathrm{~A}$ subunit to prevent SNARE protein interactions. Therefore, kinases utilize a range of mechanisms to exert either stimulatory or inhibitory effects on $\mathrm{Ca}_{V} 2.1$ function. In the present study, we have demonstrated that LRRK2 stimulates $\mathrm{Ca}_{\mathrm{V}} 2.1$ channels causing an increase in $\mathrm{Ca}^{2+}$ current density. The mechanism behind this effect appears to be due to a direct effect of LRRK2 on modulating channel gating. This direct action of LRRK2 is supported by our results showing that voltage-dependent activation is significantly shifted to more hyperpolarized potentials with LRRK2 overexpression. This would increase the proportion 


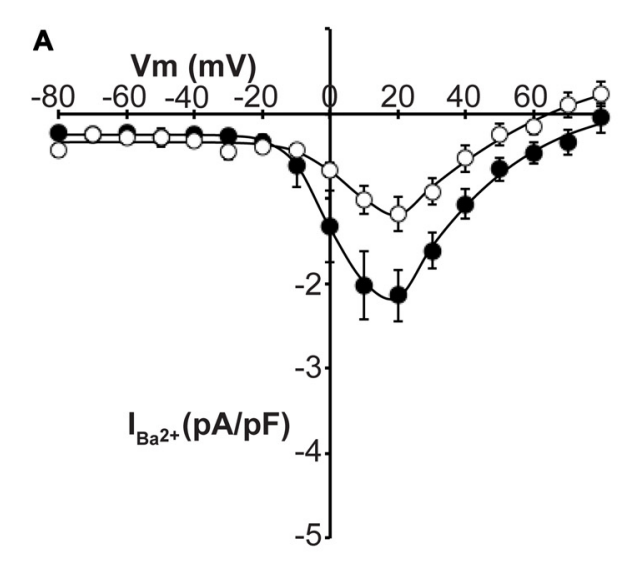

C

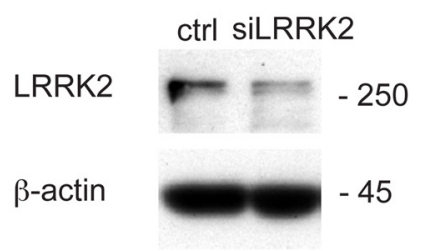

B

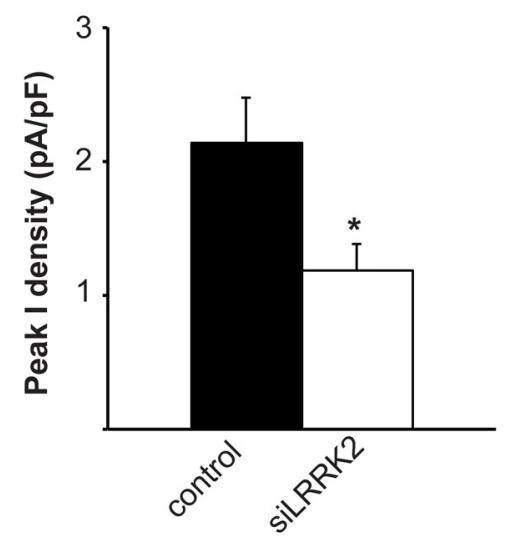

D

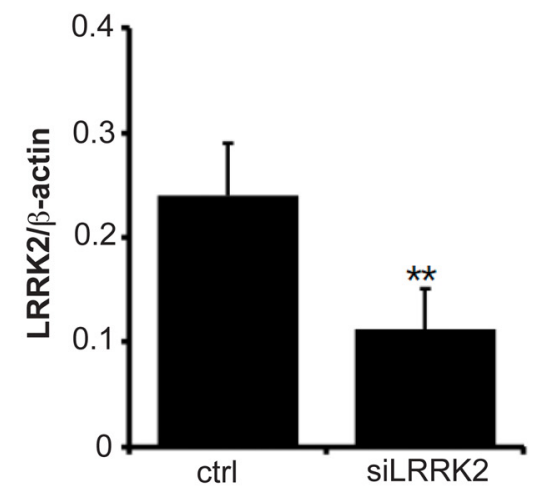

FIGURE 9 | Knockdown of endogenous LRRK2 in PC12 cells decreases native CaV channel function. (A) Silencing LRRK2 (white circles) reduces Cav current density compared to LVTH controls (solid circles; $n=10$ cells from four independent experiments). (B) Peak Ba ${ }^{2+}$ current density was significantly decreased in siLRRK2 cells compared to controls (where * indicates $p<0.05$; unpaired $t$-test). (C) PC12 cells were transfected with LVTH control (ctrl) vector or siLRRK2 vector and the expression of LRRK2 and $\beta$-actin was evaluated by western blotting. (D) The graph reports the LRRK2 protein level normalized to $\beta$-actin. Data are expressed as mean \pm SEM $\left(n=4\right.$; where ${ }^{* *}$ indicates $p<0.01$; unpaired $t$-test).

of active channels at more hyperpolarized voltages, leading to an increased current density. This indicates that LRRK2 is impacting how the channel changes conformation at the membrane in response to voltage; an effect most likely to be caused by LRRK2 interacting with the macromolecular $\mathrm{Ca}_{V} 2.1$ complex. Moreover, our co-immunoprecipitation results reveal that LRRK2 interacts with the $\mathrm{Ca}_{V} 2.1 \beta 3$ subunit. Although it is possible this could involve indirect associations via secondary or tertiary binding relationships, this is unlikely here as we were unable to co-immunoprecipitate the $\beta 3$ interacting $\alpha 1 \mathrm{~A}$ subunit. Therefore, since $\beta 3$ subunits significantly affect voltagedependent activation (Sandoz et al., 2001; He et al., 2007), we propose that LRRK2 is exerting an effect on this mode of $\mathrm{Ca}_{\mathrm{V}} 2.1$ channel gating through its interaction with the $\beta 3$ subunit. This is in agreement with the effects of another presynaptic protein, RIM1 (Kiyonaka et al., 2007), which has been shown to interact with $\mathrm{Ca}_{\mathrm{V}} \beta$ subunits to augment $\mathrm{Ca}_{\mathrm{V}}$ channel function. Interestingly, the effects of RIM1 binding on $\mathrm{Ca}_{\mathrm{V}} 2.1$ properties depended on the type of $\beta$ subunit expressed. With $\beta 3$, RIM1 slowed inactivation kinetics and shifted the voltage-dependence of inactivation but had no effect on current density or voltage dependence of activation (Kiyonaka et al., 2007). This is in agreement with our findings of a $\beta$ interacting protein altering some channel functions but not others. Taken together, our results support a direct role of LRRK2 as a $\mathrm{Ca}_{\mathrm{V}}$ channel regulatory protein interacting with the $\beta 3$ subunit to alter gating as a means to enhance $\mathrm{Ca}_{V} 2.1$ function.

Alternatively, LRRK2 could exert an increase in Cav2.1 current density by increasing channel numbers at the membrane. Increasing the translation and synthesis of $\mathrm{Cav}_{2} 2.1$ channel subunits is one potential mode for how LRRK2 might influence channel numbers. This is supported by a recent study showing LRRK2 phosphorylates the ribosomal protein s15 to increase mRNA translation (Martin et al., 2014). In addition, increased Cav2.1 channel numbers may be caused by LRRK2 regulating 
trafficking pathways responsible for determining the amount of $\mathrm{Ca}_{\mathrm{V}} 2.1$ at the plasma membrane. In this scenario, LRRK2 interactions with the $\beta$ subunit could be important as trafficking of the $\mathrm{Ca}_{V}$ channel complex from the endoplasmic reticulum to the plasma membrane is dependent on $\beta$ subunits (Altier et al., 2011; Waithe et al., 2011). Furthermore, LRRK2 has been shown to affect a variety of intracellular trafficking pathways to control the membrane expression of several different cell surface proteins (Migheli et al., 2013; Cho et al., 2014; Gómez-Suaga et al., 2014). However, given that G2019S LRRK2 seems to bind the $\mathrm{Ca}_{\mathrm{V}} 2.1$ $\beta 3$ subunit to a lesser extent, channel trafficking may not be the main target of LRRK2 activity.

A further insight into a potential mechanism is provided by our results which demonstrate that LRRK2 is required to phosphorylate a substrate in order to regulate $\mathrm{Ca}_{V} 2.1$ activity. The G2019S LRRK2 mutant that has enhanced kinase activity caused a more pronounced effect on Cav2.1 function while blocking both wt and mutant LRRK2 kinase activity with a LRRK2 inhibitor reversed these stimulatory effects. One possible interpretation of these results is that LRRK2 needs to autophosphorylate to become activated and initiate downstream effects on $\mathrm{Ca}_{\mathrm{V}} 2.1$ channels. This is supported by recent studies demonstrating that LRRK2 autophosphorylation is required for activation of LRRK2 GTPase activity that then influences interactions with LRRK2 substrates (Cirnaru et al., 2014; Law et al., 2014; Liu et al., 2016). Alternatively, LRRK2 could be directly phosphorylating $\mathrm{Ca}_{\mathrm{V}} 2.1$ proteins to alter channel function. Indeed, two of the $\mathrm{Cav}_{V} 2.1$ channel subunits used in this study ( $\alpha 1 \mathrm{~A}$ and $\beta 3$ ) have been shown to be directly phosphorylated by other serine/threonine kinases (Zamponi et al., 1997; Grueter et al., 2008; Jiang et al., 2008). A direct role for LRRK2 phosphorylating Cav2.1 subunits is more likely than indirect effects on $\mathrm{Ca}_{\mathrm{V}}$ regulatory proteins given that experiments were performed in a heterologous expression system, however, further investigation is required to precisely identify substrates of LRRK2 phosphorylation that lead to increased $\mathrm{Ca}_{V} 2.1$ channel function.

While both wt LRRK2 and the G2019S mutant appear to upregulate $\mathrm{Ca}_{V} 2.1$ function by the same mechanism, this was a specific effect of this particular kinase as we found that LRRK1 had no effect on Cav2.1 current. Therefore, the fact that LRRK1 and LRRK2 share similar leucine-rich-repeat, GTPase and kinase domains but have divergent effects on $\mathrm{Ca}_{\mathrm{V}} 2.1$ channels indicates that the mode of regulation must be uniquely intrinsic to LRRK2 and is not a general effect of a common domain interaction. This is in agreement with other LRRK2 specific effects where increasing evidence suggests these two related proteins perform distinct cellular functions by interacting with different proteins (Reyniers et al., 2014).

Interestingly, the effect of LRRK2 may not be specific to Cav2.1 channels only. We found that LRRK2 was able to upregulate endogenous $\mathrm{Ca}_{\mathrm{V}}$ current in $\mathrm{PC} 12$ cells that contain a variety of different types of $\mathrm{Ca}_{V}$ channels. Within this background of multiple types of $\mathrm{Ca}_{V}$ channel subunits, it was not possible here to discern if LRRK2 mediated increases in PC12 $\mathrm{Ca}_{V}$ current density involved alterations to activation gating. However, these results provide evidence that several types of $\mathrm{Ca}_{V}$ channels could be targeted by LRRK2. Future studies are required to identify which other types of $\mathrm{Ca}_{V}$ channels are targeted by LRRK2, the subunits involved and whether LRRK2 utilizes a common mechanism to upregulate $\mathrm{Ca}_{\mathrm{V}}$ function as we have described here. If so, this would suggest that LRRK2 is involved in a general physiological role of stimulating $\mathrm{Ca}_{V}$ channel function to influence intracellular $\mathrm{Ca}^{2+}$ signaling. This could have important downstream effects on many $\mathrm{Ca}^{2+}$ dependent cellular processes such as vesicle trafficking and autophagy. In fact, accumulating evidence describes a role for LRRK2 at the presynaptic site. For example, we have previously shown that LRRK2 influences neurotransmission acting as a scaffolding element (Piccoli et al., 2011, 2014) as well as a kinase (Cirnaru et al., 2014). If, as we have shown here in a recombinant system, synaptic calcium channels are upregulated by LRRK2, it might be expected that stimulus evoked neurotransmitter release would be increased by LRRK2 activity and further by gain-of-function mutations such as G2019S. Notably, complementary G2019S models suggest that the gain-of-function LRRK2 mutation positively modulates presynaptic release; in particular, LRRK2 knock-in mouse G2019S mutants are characterized by elevated glutamate release and synaptic transmission (Beccano-Kelly et al., 2014), primary cultures from BAC hG2019S mice demonstrate increased synaptic vesicle trafficking (Belluzzi et al., 2016) and G2019S over-expression in PC12 cells increases dopamine release (Migheli et al., 2013). Indeed, we and others have shown that reducing LRRK2 expression has a similar impact on presynaptic properties (Piccoli et al., 2011; Matta et al., 2012) with contrasting effects also reported (Arranz et al., 2015). However, it is possible that LRRK2 plays different roles while acting as a scaffold or a kinase. An intriguing hypothesis is that LRRK2 may organize a molecular hub that impairs neurotransmission by tethering synaptic vesicles via proteinprotein interactions (Piccoli et al., 2014). LRRK2 kinase activity may instead promote synaptic vesicle fusion via phosphorylation of presynaptic substrates such as snapin (Yun et al., 2013), EndophilinA (Matta et al., 2012) N-ethylmaleimide sensitive fusion (NSF; Belluzzi et al., 2016) and Cav2.1 channels (this study). Given this dual role, any perturbation to LRRK2 levels or kinase activity may influence LRRK2 control of synaptic calcium channels and vesicle dynamics and, ultimately, on downstream neurotransmission.

The effects of LRRK2 on $\mathrm{Ca}_{V}$ channels may be part of a broader role of LRRK2 in regulating $\mathrm{Ca}^{2+}$ signaling proteins as LRRK2 has been shown to activate NAADP receptors to cause $\mathrm{Ca}^{2+}$ efflux from $\mathrm{Ca}^{2+}$ stores (Gómez-Suaga et al., 2012) and stimulate $\mathrm{Na}^{+} / \mathrm{Ca}^{2+}$ exchanger activity (Yan et al., 2015). In addition to a potential role in normal $\mathrm{Ca}^{2+}$ signaling, our results may also provide further insight into LRRK2 pathophysiology. The G2019S LRRK2 mutation associated with Parkinson's disease stimulated $\mathrm{Ca}_{V} 2.1$ channels to a greater degree than wt. This mutation has also been shown to cause mitochondrial degradation in cortical neurons which could be prevented by blocking $\mathrm{Ca}^{2+}$ influx via $\mathrm{Ca}_{V}$ channels (Cherra et al., 2013). Therefore, LRRK2 mutations could disrupt normal $\mathrm{Ca}^{2+}$ signaling as an early cellular event in the development of Parkinson's disease. 
In conclusion, this study has identified a novel role for LRRK2 in regulating $\mathrm{Ca}_{V} 2.1$ channel function. Both wt and mutant LRRK2 augment Cav2.1 function that is dependent on kinase activation. This was associated with LRRK2 interacting with the $\mathrm{Ca}_{V} \beta 3$ subunit. Although further investigation is required to determine whether this involves LRRK2 directly phosphorylating $\mathrm{Ca}_{\mathrm{V}}$ subunits or having an indirect effect on channel regulatory proteins, our results provide further evidence that LRRK2 has an important regulatory role in cellular $\mathrm{Ca}^{2+}$ signaling.

\section{AUTHOR CONTRIBUTIONS}

CB, CS, MP-C and SBC performed experiments; CB, MP-C, GP and SBC analyzed data; GP and SBC designed experiments

\section{REFERENCES}

Alegre-Abarrategui, J., Christian, H., Lufino, M. M., Mutihac, R., Venda, L. L., Ansorge, O., et al. (2009). LRRK2 regulates autophagic activity and localizes to specific membrane microdomains in a novel human genomic reporter cellular model. Hum. Mol. Genet. 18, 4022-4034. doi: 10.1093/hmg/ddp346

Altier, C., Garcia-Caballero, A., Simms, B., You, H., Chen, L., Walcher, J., et al. (2011). The Cav $\beta$ subunit prevents RFP2-mediated ubiquitination and proteasomal degradation of L-type channels. Nat. Neurosci. 14, 173-180. doi: $10.1038 / \mathrm{nn} .2712$

Arranz, A. M., Delbroek, L., Van Kolen, K., Guimãraes, M. R., Mandemakers, W., Daneels, G., et al. (2015). LRRK2 functions in synaptic vesicle endocytosis through a kinase-dependent mechanism. J. Cell Sci. 128, 541-552. doi: 10. $1242 /$ jcs. 158196

Beccano-Kelly, D. A., Kuhlmann, N., Tatarnikov, I., Volta, M., Munsie, L. N., Chou, P., et al. (2014). Synaptic function is modulated by LRRK2 and glutamate release is increased in cortical neurons of G2019S LRRK2 knock-in mice. Front. Cell. Neurosci. 8:301. doi: 10.3389/fncel.2014.00301

Belluzzi, E., Gonnelli, A., Cirnaru, M. D., Marte, A., Plotegher, N., Russo, I., et al. (2016). LRRK2 phosphorylates pre-synaptic $\mathrm{N}$-ethylmaleimide sensitive fusion (NSF) protein enhancing its ATPase activity and SNARE complex disassembling rate. Mol. Neurodegener. 11:1. doi: 10.1186/s13024-015-0066-z

Bezprozvanny, I., Scheller, R. H., and Tsien, R. W. (1995). Functional impact of syntaxin on gating of N-type and Q-type calcium channels. Nature 378, 623-626. doi: 10.1038/378623a0

Braun, M., Ramracheya, R., Bengtsson, M., Zhang, Q., Karanauskaite, J., Partridge, C., et al. (2008). Voltage-gated ion channels in human pancreatic beta-cells: electrophysiological characterization and role in insulin secretion. Diabetes 57, 1618-1628. doi: 10.2337/db07-0991

Cherra, S. J., III, Steer, E., Gusdon, A. M., Kiselyov, K., and Chu, C. T. (2013). Mutant LRRK2 elicits calcium imbalance and depletion of dendritic mitochondria in neurons. Am. J. Pathol. 182, 474-484. doi: 10.1016/j.ajpath. 2012.10.027

Cho, H. J., Yu, J., Xie, C., Rudrabhatla, P., Chen, X., Wu, J., et al. (2014). Leucinerich repeat kinase 2 regulates Sec16A at ER exit sites to allow ER-Golgi export. EMBO J. 33, 2314-2331. doi: 10.15252/embj.201487807

Cirnaru, M. D., Marte, A., Belluzzi, E., Russo, I., Gabrielli, M., Longo, F., et al. (2014). LRRK2 kinase activity regulates synaptic vesicle trafficking and neurotransmitter release through modulation of LRRK2 macro-molecular complex. Front. Mol. Neurosci. 7:49. doi: 10.3389/fnmol.2014.00049

Cohen-Kutner, M., Nachmanni, D., and Atlas, D. (2010). CaV2.1 (P/Q channel) interaction with synaptic proteins is essential for depolarization-evoked release. Channels (Austin) 4, 266-277. doi: 10.4161/chan.4.4.12130

Condliffe, S. B., Corradini, I., Pozzi, D., Verderio, C., and Matteoli, M. (2010). Endogenous SNAP-25 regulates native voltage-gated calcium channels in glutamatergic neurons. J. Biol. Chem. 285, 24968-24976. doi: 10.1074/jbc. M110.145813 and wrote the article. All authors revised the manuscript and approved the final version.

\section{ACKNOWLEDGMENTS}

We would like to thank Celine Duynstee (University of Otago) for initial technical assistance. We are also grateful to Patrizia Rosa (CNR Institute, Milan, Italy) for Cav 2.1 channel constructs and Dr. Heather Melrose (Mayo Clinic, Jacksonville, FL, USA) for providing BAC hG2019S mice. This work was supported by a University of Otago Research Grant (SBC) and the Department of Physiology, University of Otago (SBC, CB and CS). GP is supported by the Michael J. Fox Foundation and by Fondazione Telethon, Italy (Grants GGP12237 and TCP14005) and is grateful to Fondazione Grigioni per il Morbo di Parkinson.

Condliffe, S. B., Fratangeli, A., Munasinghe, N. R., Saba, E., Passafaro, M., Montrasio, C., et al. (2013). The E1015K variant in the synprint region of the CaV2.1 channel alters channel function and is associated with different migraine phenotypes. J. Biol. Chem. 288, 33873-33883. doi: 10.1074/jbc.M113. 497701

DeMaria, C. D., Soong, T. W., Alseikhan, B. A., Alvania, R. S., and Yue, D. T. (2001). Calmodulin bifurcates the local Ca2+ signal that modulates P/Q-type Ca2+ channels. Nature 411, 484-489. doi: 10.1038/35078091

Deng, X., Dzamko, N., Prescott, A., Davies, P., Liu, Q., Yang, Q., et al. (2011). Characterization of a selective inhibitor of the Parkinson's disease kinase LRRK2. Nat. Chem. Biol. 7, 203-205. doi: 10.1038/nchembio.538

Dusonchet, J., Kochubey, O., Stafa, K., Young, S. M., Jr., Zufferey, R., Moore, D. J., et al. (2011). A rat model of progressive nigral neurodegeneration induced by the Parkinson's disease-associated G2019S mutation in LRRK2. J. Neurosci. 31, 907-912. doi: 10.1523/JNEUROSCI.5092-10.2011

Gloeckner, C. J., Kinkl, N., Schumacher, A., Braun, R. J., O’Neill, E., Meitinger, T., et al. (2006). The Parkinson disease causing LRRK2 mutation I2020T is associated with increased kinase activity. Hum. Mol. Genet. 15, 223-232. doi: $10.1093 / \mathrm{hmg} / \mathrm{ddi} 439$

Gómez-Suaga, P., Luzón-Toro, B., Churamani, D., Zhang, L., Bloor-Young, D., Patel, S., et al. (2012). Leucine-rich repeat kinase 2 regulates autophagy through a calcium-dependent pathway involving NAADP. Hum. Mol. Genet. 21, 511-525. doi: 10.1093/hmg/ddr481

Gómez-Suaga, P., Rivero-Rios, P., Fdez, E., Blanca Ramirez, M., Ferrer, I., Aiastui, A., et al. (2014). LRRK2 delays degradative receptor trafficking by impeding late endosomal budding through decreasing Rab7 activity. Hum. Mol. Genet. 23, 6779-6796. doi: 10.1093/hmg/ddu395

Greggio, E., Lewis, P. A., Van Der Brug, M. P., Ahmad, R., Kaganovich, A., Ding, J., et al. (2007). Mutations in LRRK2/dardarin associated with Parkinson disease are more toxic than equivalent mutations in the homologous kinase LRRK1. J. Neurochem. 102, 93-102. doi: 10.1111/j.1471-4159.2007. 04523.x

Grueter, C. E., Abiria, S. A., Wu, Y., Anderson, M. E., and Colbran, R. J. (2008). Differential regulated interactions of calcium/calmodulin-dependent protein kinase II with isoforms of voltage-gated calcium channel beta subunits. Biochemistry 47, 1760-1767. doi: 10.1021/bi701755q

He, L. L., Zhang, Y., Chen, Y. H., Yamada, Y., and Yang, J. (2007). Functional modularity of the $\beta$-subunit of voltage-gated Ca2+ channels. Biophys. J. 93, 834-845. doi: 10.1529/biophysj.106.101691

Jiang, X., Lautermilch, N. J., Watari, H., Westenbroek, R. E., Scheuer, T., and Catterall, W. A. (2008). Modulation of CaV2.1 channels by $\mathrm{Ca} 2+/$ calmodulin-dependent protein kinase II bound to the $\mathrm{C}$-terminal domain. Proc. Natl. Acad. Sci. U S A 105, 341-346. doi: 10.1073/pnas.07102 13105

Kiyonaka, S., Wakamori, M., Miki, T., Uriu, Y., Nonaka, M., Bito, H., et al. (2007). RIM1 confers sustained activity and neurotransmitter vesicle anchoring to presynaptic Ca2+ channels. Nat. Neurosci. 10, 691-701. doi: 10.1038/nn1904 
Kreiner, L., and Lee, A. (2006). Endogenous and exogenous Ca2+ buffers differentially modulate Ca2+-dependent inactivation of $\mathrm{Ca}(\mathrm{v}) 2.1 \mathrm{Ca} 2+$ channels. J. Biol. Chem. 281, 4691-4698. doi: 10.1074/jbc.m511971200

Law, B. M., Spain, V. A., Leinster, V. H., Chia, R., Beilina, A., Cho, H. J., et al. (2014). A direct interaction between leucine-rich repeat kinase 2 and specific beta-tubulin isoforms regulates tubulin acetylation. J. Biol. Chem. 289, 895-908. doi: 10.1074/jbc.m113.507913

Li, Y., Liu, W., Oo, T. F., Wang, L., Tang, Y., Jackson-Lewis, V., et al. (2009). Mutant LRRK2(R1441G) BAC transgenic mice recapitulate cardinal features of Parkinson's disease. Nat. Neurosci. 12, 826-828. doi: 10.1038/nn.2349

Liu, H., Felix, R., Gurnett, C. A., De Waard, M., Witcher, D. R., and Campbell, K. P. (1996). Expression and subunit interaction of voltage-dependent Ca2+ channels in PC12 cells. J. Neurosci. 16, 7557-7565.

Liu, Z., Mobley, J. A., DeLucas, L. J., Kahn, R. A., and West, A. B. (2016). LRRK2 autophosphorylation enhances its GTPase activity. FASEB J. 30, 336-347. doi: 10.1096/fj.15-277095

MacLeod, D. A., Rhinn, H., Kuwahara, T., Zolin, A., Di Paolo, G., McCabe, B. D., et al. (2013). RAB7L1 interacts with LRRK2 to modify intraneuronal protein sorting and Parkinson's disease risk. Neuron 77, 425-439. doi: 10. 1016/j.neuron.2012.11.033

Mahapatra, S., Calorio, C., Vandael, D. H., Marcantoni, A., Carabelli, V., and Carbone, E. (2012). Calcium channel types contributing to chromaffin cell excitability, exocytosis and endocytosis. Cell Calcium 51, 321-330. doi: 10. 1016/j.ceca.2012.01.005

Martin, I., Kim, J. W., Lee, B. D., Kang, H. C., Xu, J. C., Jia, H., et al. (2014). Ribosomal protein 15 phosphorylation mediates LRRK2 neurodegeneration in Parkinson's disease. Cell 157, 472-485. doi: 10.1016/j.cell.2014.01.064

Matta, S., Van Kolen, K., Da Cunha, R., Van Den Bogaart, G., Mandemakers, W., Miskiewicz, K., et al. (2012). LRRK2 controls an EndoA phosphorylation cycle in synaptic endocytosis. Neuron 75, 1008-1021. doi: 10.1016/j.neuron.2012.08. 022

Meixner, A., Boldt, K., Van Troys, M., Askenazi, M., Gloeckner, C. J., Bauer, M., et al. (2011). A quick screen for LRRK2 interaction partners-leucine-rich repeat kinase 2 is involved in actin cytoskeleton dynamics. Mol. Cell. Proteomics 10:M110.001172. doi: 10.1074/mcp.m110.001172

Melrose, H. L., Dächsel, J. C., Behrouz, B., Lincoln, S. J., Yue, M., Hinkle, K. M., et al. (2010). Impaired dopaminergic neurotransmission and microtubuleassociated protein tau alterations in human LRRK2 transgenic mice. Neurobiol. Dis. 40, 503-517. doi: 10.1016/j.nbd.2010.07.010

Migheli, R., Del Giudice, M. G., Spissu, Y., Sanna, G., Xiong, Y., Dawson, T. M., et al. (2013). LRRK2 affects vesicle trafficking, neurotransmitter extracellular level and membrane receptor localization. PLoS One 8:e77198. doi: 10. 1371/journal.pone.0077198

Paisán-Ruiz, C., Jain, S., Evans, E. W., Gilks, W. P., Simon, J., Van Der Brug, M., et al. (2004). Cloning of the gene containing mutations that cause PARK8linked Parkinson's disease. Neuron 44, 595-600. doi: 10.1016/j.neuron.2004.10. 023

Piccoli, G., Condliffe, S. B., Bauer, M., Giesert, F., Boldt, K., De Astis, S., et al. (2011). LRRK2 controls synaptic vesicle storage and mobilization within the recycling pool. J. Neurosci. 31, 2225-2237. doi: 10.1523/JNEUROSCI.3730-10. 2011

Piccoli, G., Onofri, F., Cirnaru, M. D., Kaiser, C. J., Jagtap, P., Kastenmuller, A., et al. (2014). Leucine-rich repeat kinase 2 binds to neuronal vesicles through protein interactions mediated by its C-terminal WD40 domain. Mol. Cell. Biol. 34, 2147-2161. doi: 10.1128/MCB.00914-13

Plummer, M. R., Logothetis, D. E., and Hess, P. (1989). Elementary properties and pharmacological sensitivities of calcium channels in mammalian peripheral neurons. Neuron 2, 1453-1463. doi: 10.1016/0896-6273(89)90191-8

Qian, J., and Noebels, J. L. (2001). Presynaptic Ca2+ channels and neurotransmitter release at the terminal of a mouse cortical neuron. J. Neurosci. 21, 3721-3728.

Rajakulendran, S., Kaski, D., and Hanna, M. G. (2012). Neuronal P/Q-type calcium channel dysfunction in inherited disorders of the CNS. Nat. Rev. Neurol. 8, 86-96. doi: 10.1038/nrneurol.2011.228
Reyniers, L., Del Giudice, M. G., Civiero, L., Belluzzi, E., Lobbestael, E., Beilina, A., et al. (2014). Differential protein-protein interactions of LRRK1 and LRRK2 indicate roles in distinct cellular signaling pathways. J. Neurochem. 131, 239-250. doi: 10.1111/jnc.12798

Sandoz, G., Bichet, D., Cornet, V., Mori, Y., Felix, R., and De Waard, M. (2001). Distinct properties and differential beta subunit regulation of two C-terminal isoforms of the P/Q-type Ca2+-channel $\alpha_{1 \mathrm{~A}}$ subunit. Eur. J. Neurosci. 14, 987-997. doi: 10.1046/j.0953-816x.2001.01728.x

Serra, S. A., Cuenca-León, E., Llobet, A., Rubio-Moscardo, F., Plata, C., Carreño, O., et al. (2010). A mutation in the first intracellular loop of CACNA1A prevents P/Q channel modulation by SNARE proteins and lowers exocytosis. Proc. Natl. Acad. Sci. U S A 107, 1672-1677. doi: 10.1073/pnas.09083 59107

Tomizawa, K., Ohta, J., Matsushita, M., Moriwaki, A., Li, S. T., Takei, K., et al. (2002). Cdk5/p35 regulates neurotransmitter release through phosphorylation and downregulation of P/Q-type voltage-dependent calcium channel activity. J. Neurosci. 22, 2590-2597.

Tong, Y., Yamaguchi, H., Giaime, E., Boyle, S., Kopan, R., Kelleher, R. J., et al. (2010). Loss of leucine-rich repeat kinase 2 causes impairment of protein degradation pathways, accumulation of alpha-synuclein and apoptotic cell death in aged mice. Proc. Natl. Acad. Sci. U S A 107, 9879-9884. doi: 10. 1073/pnas.1004676107

Waithe, D., Ferron, L., Page, K. M., Chaggar, K., and Dolphin, A. C. (2011). Beta-subunits promote the expression of $\mathrm{Ca}(\mathrm{V}) 2.2$ channels by reducing their proteasomal degradation. J. Biol. Chem. 286, 9598-9611. doi: 10.1074/jbc. M110.195909

West, A. B., Moore, D. J., Biskup, S., Bugayenko, A., Smith, W. W., Ross, C. A., et al. (2005). Parkinson's disease-associated mutations in leucine-rich repeat kinase 2 augment kinase activity. Proc. Natl. Acad. Sci. U S A 102, 16842-16847. doi: 10. 1073/pnas.0507360102

Westenbroek, R. E., Hoskins, L., and Catterall, W. A. (1998). Localization of $\mathrm{Ca} 2+$ channel subtypes on rat spinal motor neurons, interneurons and nerve terminals. J. Neurosci. 18, 6319-6330.

Yan, J., Almilaji, A., Schmid, E., Elvira, B., Shimshek, D. R., Van Der Putten, H., et al. (2015). Leucine-rich repeat kinase 2-sensitive $\mathrm{Na}+/ \mathrm{Ca} 2+$ exchanger activity in dendritic cells. FASEB J. 29, 1701-1710. doi: 10.1096/fj.14264028

Yun, H. J., Park, J., Ho, D. H., Kim, H., Kim, C. H., Oh, H., et al. (2013). LRRK2 phosphorylates Snapin and inhibits interaction of Snapin with SNAP-25. Exp. Mol. Med. 45:e36. doi: 10.1038/emm.2013.68

Zamponi, G. W., Bourinet, E., Nelson, D., Nargeot, J., and Snutch, T. P. (1997). Crosstalk between G proteins and protein kinase C mediated by the calcium channel alphal subunit. Nature 385, 442-446. doi: 10.1038/38 $5442 \mathrm{a} 0$

Zhu, L. Q., Liu, D., Hu, J., Cheng, J., Wang, S. H., Wang, Q., et al. (2010). GSK3 beta inhibits presynaptic vesicle exocytosis by phosphorylating P/Q-type calcium channel and interrupting SNARE complex formation. J. Neurosci. 30, 3624-3633. doi: 10.1523/JNEUROSCI.5223-09.2010

Zimprich, A., Biskup, S., Leitner, P., Lichtner, P., Farrer, M., Lincoln, S., et al. (2004). Mutations in LRRK2 cause autosomal-dominant parkinsonism with pleomorphic pathology. Neuron 44, 601-607. doi: 10.1016/j.neuron.2004. 11.005

Conflict of Interest Statement: The authors declare that the research was conducted in the absence of any commercial or financial relationships that could be construed as a potential conflict of interest.

Copyright (c) 2016 Bedford, Sears, Perez-Carrion, Piccoli and Condliffe. This is an open-access article distributed under the terms of the Creative Commons Attribution License (CC BY). The use, distribution and reproduction in other forums is permitted, provided the original author(s) or licensor are credited and that the original publication in this journal is cited, in accordance with accepted academic practice. No use, distribution or reproduction is permitted which does not comply with these terms. 